\title{
PROCESSOS EROSIVOS COSTEIROS DA PRAIA DE BOA VIAGEM
}

\author{
shoreline erosion in the Boa Viagem beach, Recife-PE \\ Luis Augusto de Gois * \\ Niédja Maria Galvão Araújo e Oliveira ** \\ Valdir do Amaral Vaz Manso ***
}

\begin{abstract}
Resumo
Em todo o mundo, as zonas costeiras sofrem com as atividades antropogênicas, impondo-lhes severos impactos e, em alguns casos, extrapolando os limites de seus recursos naturais e de sua resiliência. O desequilíbrio dessas áreas, sobretudo os processos erosivos, tem impulsionado a adoção de uma sucessão de medidas pontuais e muitas vezes inadequadas do ponto de vista técnico e ambiental. Nesse sentido, este estudo tem como objetivo analisar a evolução dos processos de erosão costeira na Praia de Boa Viagem, município de Recife-PE, permitindo, por meio da investigação bibliográfica, do levantamento e monitoramento de dados, maior compreensão das variáveis envolvidas na imputação desses processos, avaliando o comportamento da estrutura de contenção ali inserida, e sua ascendência sobre o ambiente, bem como os resultados obtidos com sua implantação.
\end{abstract}

Palavras-chave: Defesa costeira, Erosão costeira, Praia de Boa Viagem.

\section{Abstract}

Throughout the world, the shore line has suffered with anthropogenic activities which have imposed severe impacts to it and, in some cases, extrapolated the limits of its natural resources and resilience. The unbalancing of these areas, especially the erosion processes, has driven the adoption of a series of not rarely inadequate measures, in terms of technical and environmental views. In this sense, this study aims to analyze the evolution of the shore erosion processes of the Boa Viagem Beach, in the municipality of Recife-PE, allowing, through literature research and the search of monitoring data, a greater understanding of the variables involved in these processes, evaluating the behavior of the containment structure therein inserted, and also the influence of the environment and the results obtained from its deployment.

Key words: Coastal defense, Shoreline erosion, Boa Viagem Beach.

\section{Resumen}

En todo el mundo las zonas costeras sufren con las actividades antrópicas, les causando severos impactos y, en algunos casos, extrapolando los límites de sus recursos naturales y su capacidad de recuperación. El desequilibrio de estas áreas, especialmente los procesos erosivos, tiene impulsado la adopción de una serie de medidas puntuales, y muchas veces inadecuadas técnicamente y ambientalmente. En este sentido, este estudio tiene como objetivo analizar la evolución de los procesos de erosión costera en la Playa de Boa Viagem, en la ciudad de Recife-PE, permitiendo, a través de la investigación y del levantamiento y acompañamiento de datos, una mayor comprensión de las variables envueltas en la imputación de estos procesos, evaluando el comportamiento de la estructura de contención allí introducida, y la influencia de la misma sobre el medio ambiente, así como los resultados obtenidos a partir de su implantación.

Palabras-claves:Defesa costera, Erosión costera, Playa de Boa Viagem.

(*) Mestre em Tecnologia Ambiental, Instituto Tecnológico de Pernambuco - Rua Hamilton Ribeiro, 175 - Campo Grande, CEP 52.031-090, Recife/ (PE), Brasil. Tel: + 5581 8601-5605 - luis.de.gois@uol.com.br

(**) Prof ${ }^{\mathrm{a}}$. Dr ${ }^{\mathrm{a}}$. Titular em Geografia Física, Universidade de Pernambuco - R. Prof. Américo Brandão, 64 - Centro, CEP 55.800000, Nazaré da Mata (PE), Brasil. Tel: + 5581 9996-7037 - noliveira825@gmail.com

(**) Prof. Dr. da Universidade Federal de Pernambuco - Avenida Hélio Ramos, s/n, Cidade Universitária, Recife/PE, Brasil. Tel: + 558199459166 - vazmanso@uol.com.br 


\section{INTRODUÇÃO}

As zonas costeiras representam em todo o mundo o espaço de maior procura pelo uso e ocupação em países litorâneos. O forte apelo paisagístico, associado à imensa riqueza biológica e à diversidade de opções de uso, tem feito dessas áreas, ao longo do tempo, um espaço de permanente atratividade para a ocupação humana, além de se constituir uma relevante fonte socioeconômica, mediante a produção de receitas por meio da pesca, da geração de energia, da especulação imobiliária, das opções de transporte e das atividades portuárias, recreativas e de lazer, entre outras.

Contudo, o litoral é uma área que, por se situar na interface entre o continente e o oceano, está submetido a intensas e constantes alterações impostas por essas duas massas, o que o torna essencialmente dinâmico e simultaneamente vulnerável. Não obstante a grande variedade de fenômenos de ocorrências naturais nessa porção de interação, tais como ventos, ondas, correntes e marés - fenômenos esses que respondem diretamente pelo processo de modelagem da costa -, o litoral ainda está sujeito à ocorrência de eventos de tempestade, ressaca e de possíveis alterações meteorológicas que, na maioria das vezes, estão associadas a interferências exercidas no comportamento dos ambientes costeiros.

Dentre as consequências decorrentes do desequilíbrio nas zonas costeiras, a mais impactante, do ponto de vista ambiental, social e econômico, é a alteração no balanço sedimentar, principalmente quando a quantidade de sedimentos que chega ao ambiente é inferior à quantidade que sai, promovendo o desencadeamento dos processos de erosão das costas.

Os processos erosivos costeiros estão presentes em todo o mundo. Isso se faz sentir, em grande parte, em razão de que a maior parte da população mundial vive em zonas costeiras.

Em Pernambuco, segundo dados do Censo 2010 do Instituto Brasileiro de Geografia e Estatística (IBGE, 2011), a faixa litorânea, composta por 20 municípios, distribuídos ao longo de 187 $\mathrm{km}$, concentra uma população de cerca de 3,9 milhões de habitantes, o que representa 44,4\% da população estadual, e uma densidade demográfica média da zona costeira de aproximadamente $887,62 \mathrm{hab} . / \mathrm{km}^{2}$.

A intensificação dos processos erosivos ao longo do litoral de Pernambuco, especificamente na Região Metropolitana do Recife (RMR), tem atingido níveis que margeiam o colapso, e, com isso, levado à criação de uma sucessão de medidas pontuais, muitas vezes inadequadas do ponto de vista técnico e ambiental, adotadas no afã de se preservar o patrimônio público e privado (ruas, calçadões, casas, entre outros), perante situações emergenciais.

Pela importância da preservação desse bem comum, e em razão dos propósitos do gerenciamento costeiro, de forma conjunta, estão sendo concentrados esforços e ações de gestão da administração pública do estado de Pernambuco e dos municípios atingidos, com o objetivo de promover a concepção de técnicas capazes de proporcionar a proteção e a recuperação dos espaços costeiros.

Nesse sentido, este estudo tem como objetivo produzir um conjunto de dados e informações referentes à evolução dos processos erosivos costeiros que acometeram a Praia de Boa Viagem, Recife-PE, desde meados dos anos 1990, oferecendo elementos que permitam maior compreensão das variáveis envolvidas na imputação desses processos, além de apresentar uma síntese detalhada do comportamento da estrutura de contenção ali inserida, e de sua ascendência sobre o ambiente costeiro, bem como os resultados obtidos com sua implantação.

\section{CARACTERIZAÇÃO GERAL DA ÁREA}

A área de elaboração deste estudo corresponde à Praia de Boa Viagem, limitada ao sul pelas coordenadas UTM 289655 e 9098062 e ao norte pelas coordenadas UTM 290931e 9101219, segmento litorâneo pertencente à zona costeira da RMR (Figura 1). 

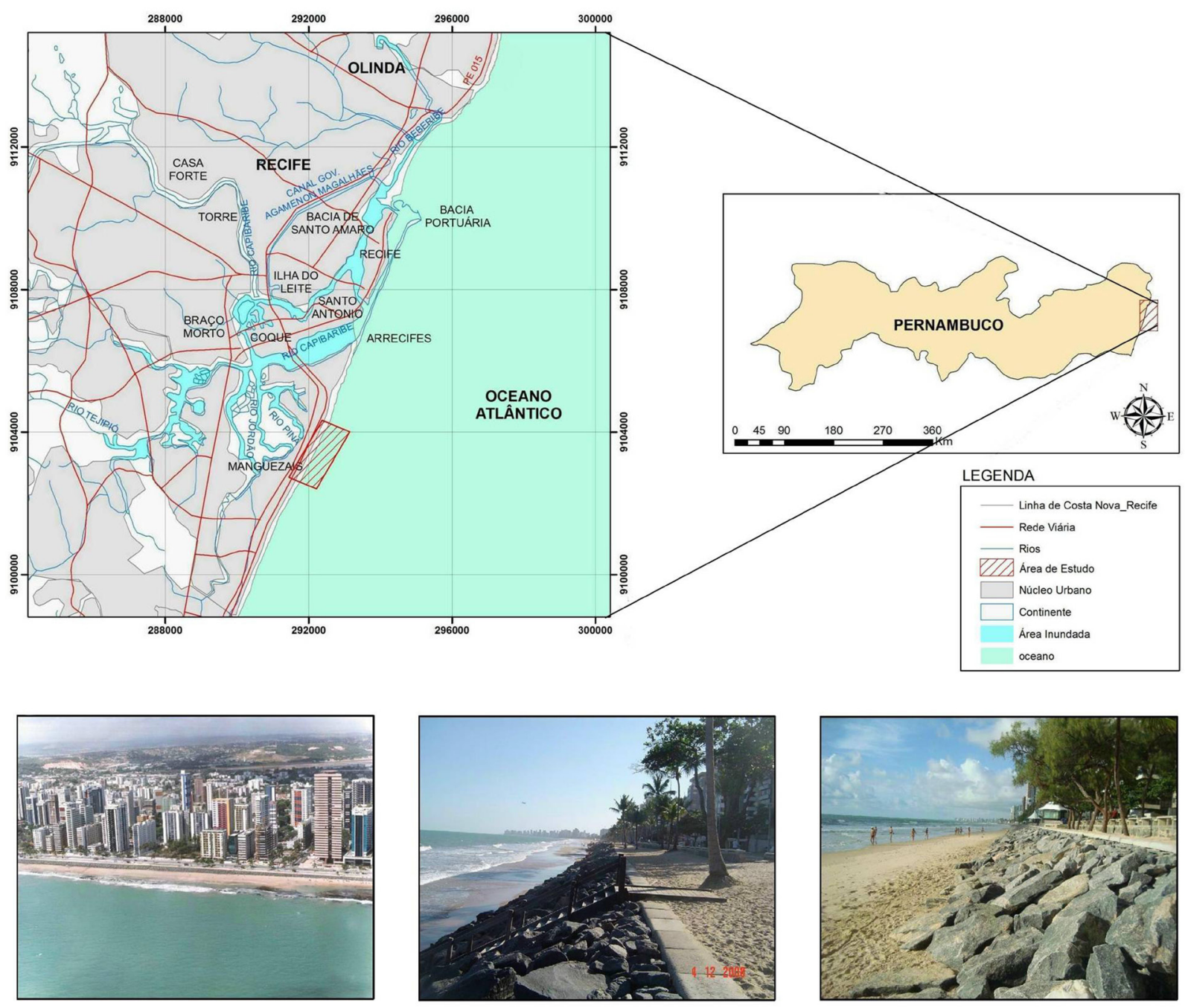

Figura 1 - Localização da área de estudo Fonte: Autoria própria, 2012

\section{A REGIÃO COSTEIRA DE PERNAMBUCO}

O clima que predomina na zona costeira de Pernambuco, segundo a classificação de Köppen (1948), é do tipo As', quente e úmido, com temperatura média anual variando entre $25^{\circ} \mathrm{C}$ (mínima) e $30^{\circ} \mathrm{C}$ (máxima), com amplitude térmica anual da ordem de $5^{\circ} \mathrm{C}$.

A vegetação litorânea da zona costeira do estado de Pernambuco representa-se pelos campos de restinga, mata de restinga, mata atlântica, cerrado e, nas áreas que se encontram sob a influência direta das marés, pela presença dos manguezais.

A costa de Pernambuco é considerada do tipo meso-maré, dominada por ondas e pela ação constante dos ventos alísios vindos predominantemente de E-SE no inverno (abril a setembro) e de E-NE durante o verão (outubro a março).

A plataforma continental de Pernambuco tem majoritariamente uma largura reduzida, com média de 35,0 km, apresentando pouca profundidade e declividade suave. O baixo índice de erosão continental e a pequena taxa de sedimentação marinha na plataforma podem ser responsáveis pela reduzida largura, enquanto a pouca profundidade é atribuída à ineficiência de processos marinhos durante o Pleistoceno, com evidência de neotectonismo. É possível, ainda, que a Corrente do Brasil possa, em parte, explicar o modesto desenvolvimento da plataforma, similar ao que ocorreu com a plataforma sudeste de Angola (MANSO et al., 2003). 
A composição sedimentar da plataforma continental é predominantemente constituída por sedimentos carbonáticos orgânicos que, segundo Coutinho (1976), é resultado da interação dos seguintes fatores:

a) plataforma estreita, rasa, águas quentes, salinidade elevada e ação das correntes;

b) predominância de clima semiárido no interior do continente, resultando no pequeno aporte de sedimento à plataforma e, consequentemente, presença de substrato duro, desprovido de sedimento fino, ideal para fixação da epifauna e da epiflora;

c) fraco desenvolvimento de corais hermatípicos;

d) fenômeno de competição, algas calcárias versus corais.

Um dos traços morfológicos mais característicos do litoral é a presença constante de beachrocks (linhas de recifes) na plataforma continental interna, paralelos à costa (Figura 2).

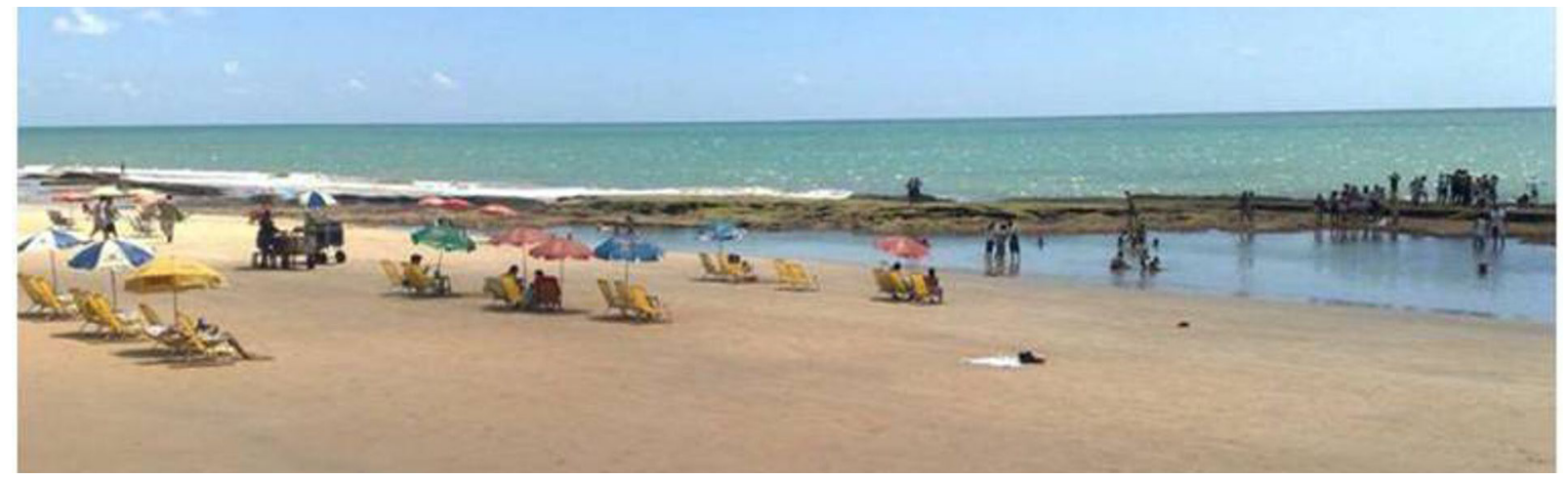

Figura 2 - Praia de Boa Viagem: presença de beachrocks na costa pernambucana Fonte: Gois (2011)

Essas formações, além de se constituírem uma proteção natural à costa, absorvendo parte da energia das ondas incidentes, exercem uma forte influência no padrão das correntes e servem de substrato para o desenvolvimento de algas e corais, que, por sua vez, formam recifes, geralmente, de forma e contorno irregulares. Essas formações recifais desempenham papel importante na morfologia recente da costa.

\section{GEOLOGIA E GEOMORFOLOGIA COSTEIRA DE PERNAMBUCO}

\section{Geologia costeira de Pernambuco}

A costa do estado de Pernambuco apresenta um caráter transgressivo jovem, com predominância de estuários, devido principalmente ao pequeno aporte de sedimentos fluviais. A presença de mangues nos estuários é marcante, sendo reflexo de uma costa com influência de marés.

Constitui-se outra característica marcante do litoral de Pernambuco a ausência quase total de dunas ao longo da planície costeira, refletindo a falta de condições favoráveis à acumulação desses depósitos, ou seja, a existência de grandes praias arenosas associadas a um clima árido e à escassez de vegetação.

$\mathrm{Na}$ área costeira, podem ser observadas as unidades geológicas desde o Mesozóico que retratam a sedimentação ocorrida nas Bacias de Pernambuco e Paraíba durante a separação das placas sul-americana e africana até unidades que mostram a sedimentação Quaternária. Segundo Nascimento (2003, p. 17): "A evolução tectono-sedimentar da Bacia de Pernambuco está diretamente associada com a ruptura dos continentes sul-americano e africano no decorrer da abertura do Oceano Atlântico Sul, cujo rifteamento maior se deu no cretáceo inferior." 


\section{Geologia da área de estudo}

A cidade de Recife, área de desenvolvimento deste estudo, localiza-se na Bacia de Pernambuco, que se estende por todo o litoral sul, delimitando-se ao norte pelo Lineamento Pernambuco e ao sul pelo Alto de Maragogi-Barreiras (Figura 3).

Essa bacia, anteriormente contextualizada no conglomerado Bacia de Pernambuco-Paraíba, caracteriza-se por apresentar uma expressiva seção rifte, vulcanosedimentar, não observada ao norte do Recife na Bacia da Paraíba.

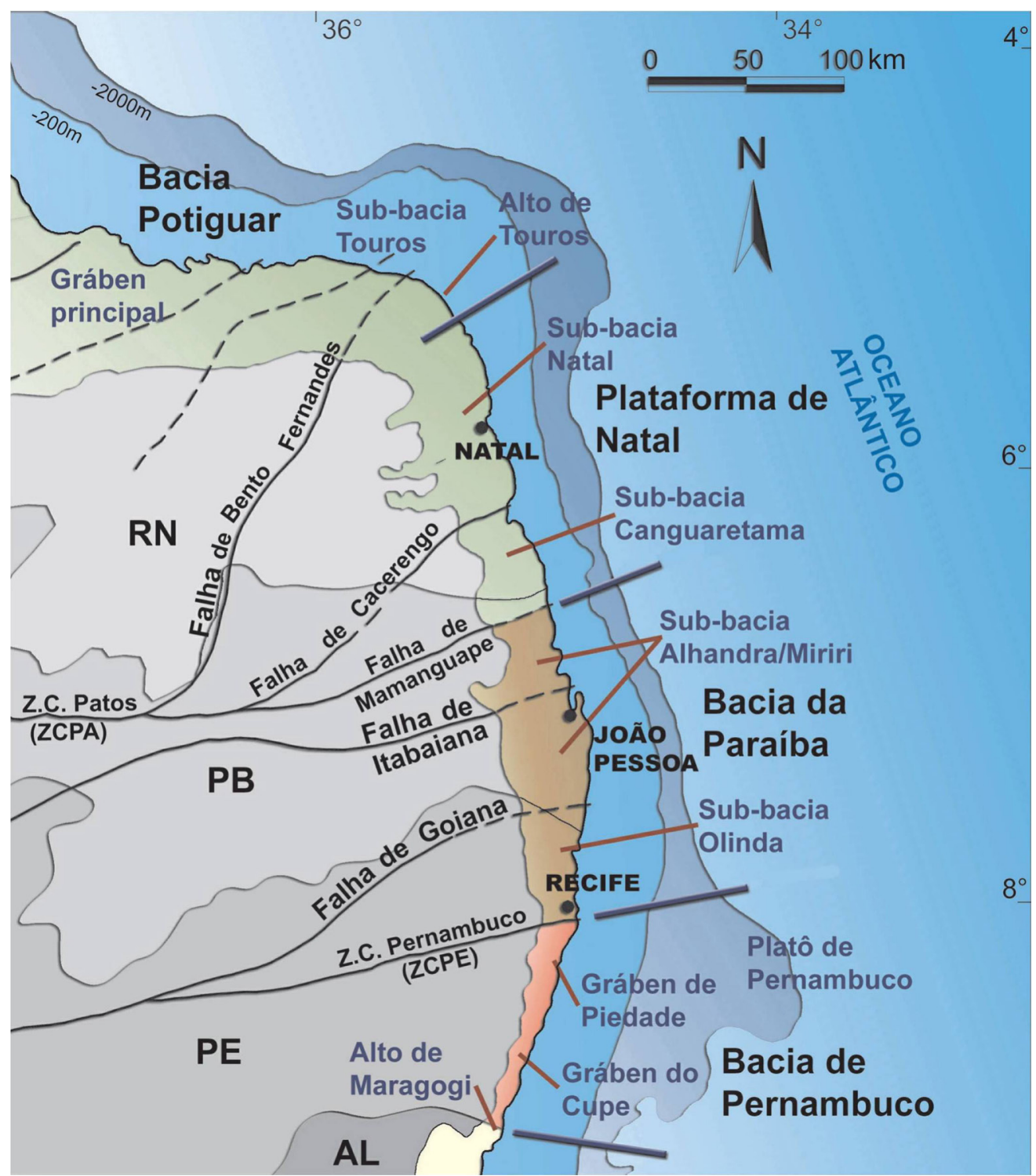

Figura 3 - Bacias de Pernambuco e da Paraíba Fonte: Barbosa; Lima Filho (2006)

\section{Geologia do quaternário}

Durante o quaternário, ocorreram eventos de variações climáticas extremas alternando períodos de glaciação, intercalados por períodos muito quentes, que proporcionaram grandes flutuações do nível do mar, ocasionando transgressões e regressões marinhas.

Segundo o MAI: "A sedimentação de ambientes costeiros está diretamente relacionada com as variações do nível do mar, o espaço de acomodação e o suprimento sedimentar." (PROJETO MONITORAMENTO AMBIENTAL INTEGRADO, 2009). 
No Brasil, os depósitos quaternários associam-se às bacias hidrográficas, que drenam bacias sedimentares homônimas (Amazonas, Paraná e Parnaíba), ou as planícies costeiras (SUGUIO, 2005).

Na região costeira de Pernambuco, segundo Dominguez et al. (1990, p. 213-214):

[...] são aí encontrados testemunhos de dois grandes episódios transgressivos quaternários. O primeiro, pleistocênico, com um máximo atingido há 120.000 anos A.P., é representado por terraços marinhos com alturas de 7 a $11 \mathrm{~m}$ acima da preamar atual e, o segundo, holocênico, com um máximo atingido há 5.000 anos A.P., apresenta um maior numero de testemunhos, na forma de: 1. terraços marinhos, que alcançam alturas de até $5 \mathrm{~m}$ acima da preamar atual; 2. depósitos lagunares; 3 . Recifes de corais e de algas coralinas; e 4 . bancos de arenito.

\section{Geomorfologia costeira de Pernambuco}

Ao longo da costa pernambucana, o comportamento litológico apresenta natureza diferenciada com predomínio, ao norte, da Superfície dos Tabuleiros e da Planície Costeira, enquanto ao sul, há uma presença do Domínio Colinoso em substituição à Superfície dos Tabuleiros.

Segundo Muehe (2006), a costa de Pernambuco insere-se na região Nordeste no macrocompartimento denominado pelo autor de "Costa dos Tabuleiros Norte", que se estende "do cabo Calcanhar ao Porto de Pedras".

\section{Peculiaridades da área de estudo}

Recife, capital do estado de Pernambuco, localiza-se no Nordeste do Brasil, tem uma área de $218,50 \mathrm{~km}^{2}$ e se situa a $08^{\circ} 04^{\prime} 03^{\prime \prime}$ de latitude S e $34^{\circ} 55^{\prime} 00^{\prime \prime}$ de longitude W. Nesse espaço vivem 1.536.934 hab., com densidade demográfica de 7.037,61 hab./km.

A vegetação que caracteriza a cidade do Recife compõe-se de mata, capoeirinha, vegetação arbustiva, coqueiral e manguezal. A altitude média da cidade do Recife é de 4 metros, embora apresente algumas áreas que se situam abaixo desse nível. A hidrografia da cidade do Recife se desenvolveu essencialmente sobre ilhas e áreas alagadiças, por essa razão, encontra-se naturalmente sob a influência das águas. O sistema hidrográfico que banha a planície da cidade do Recife compõe-se basicamente pelas bacias hidrográficas dos rios Tejipió (Jordão e Pina), Beberibe e Capibaribe.

O litoral do Recife conta com aproximadamente 9 quilômetros de extensão, compreendendo as praias de Boa Viagem, Pina e Brasília Teimosa, respectivamente de sul para norte, sendo a primeira praia, objeto deste estudo. Esse segmento litorâneo apresenta feições distintas no que se refere à largura da praia seca (pós-praia), à presença de dunas frontais, às linhas de vegetação, à escarpa de pós-praia e à presença de recifes e de estruturas artificiais.

A variação de comportamento do litoral recifense, principalmente no que se refere à largura da faixa de praia, favoreceu a identificação de cinco setores ao longo da costa (Figura 4).

Esses setores, distribuídos sequencialmente de sul para norte, caracterizam-se da seguinte forma:

Setor 1 - esse trecho de costa, situado entre a divisa Recife-Jaboatão dos Guararapes e o Clube da Aeronáutica de Recife, tem uma extensão de cerca de 800 metros e apresenta uma pós-praia bem desenvolvida, com aproximadamente 20 metros de largura, vegetação rasteira típica e, em algumas áreas, a ocorrência de pequenas dunas frontais. Esse setor caracteriza-se, ainda, por apresentar uma escarpa de preamar bem delimitada, separando o amplo estirâncio; tem, ainda, uma faixa arenosa estável com tendência à progradação e se observa a ausência da primeira linha de recifes na antepraia.

Setor 2 - compreendido entre o Clube da Aeronáutica do Recife e a Rua Coronel Benedito Chaves, esse setor apresenta uma extensão da ordem de 2.500 metros e se caracteriza pela ausência de pós-praia e presença de um enrocamento aderente estabilizando a linha de costa. A partir da Rua Engenheiro Zael Diógenes, ponto médio desse setor, ocorrem os regis- 
tros da primeira linha de recifes, porém de forma isolada e bastante descontínua em direção ao norte, onde se apresentam mais desenvolvidos. O extremo norte desse trecho, até 2010, representava a área de maior gravidade para o litoral do Recife, em razão do acentuado processo de recuo da linha de costa, inclusive com ocorrências de desmoronamento de árvores e de áreas da urbanização, quando, em setembro de 2010, a prefeitura optou por realizar a obra de prolongamento da estrutura de proteção existente (enrocamento aderente) em 400 metros, visando estabilizar a linha de costa nessa área.

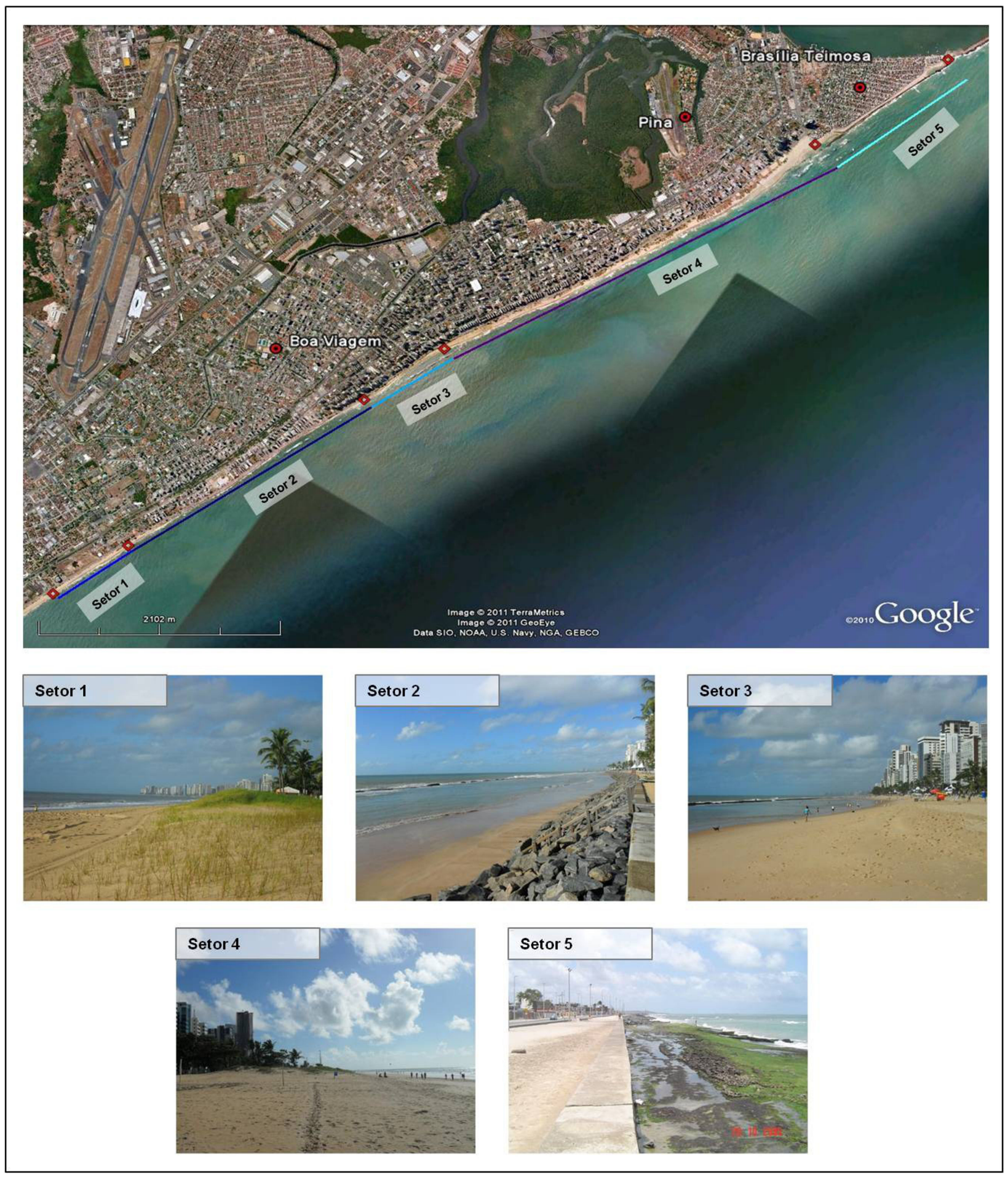

Figura 4 - Setores do litoral recifense Fonte: Adaptado de Gois (2011) 
Setor 3 - $\quad$ esse setor, que se caracteriza por um modesto acréscimo na faixa de pós-praia, porém, ainda reduzido pela presença de uma escarpa de preamar bem marcada, e por apresentar um estirâncio amplo e a presença de uma linha de recifes mais desenvolvida, está compreendido entre a Rua Coronel Benedito Chaves e a Rua Bruno Veloso, com uma extensão de aproximadamente 850 metros.

Setor 4 - $\quad$ estende-se da Rua Bruno Veloso até as imediações da Avenida Antônio de Goes, no bairro do Pina, com uma extensão em torno de 3.800 metros e se caracteriza por apresentar uma pós-praia bem desenvolvida, variando entre 40 e 100 metros, com a presença de dunas frontais e vegetação. Nesse setor encontra-se a área mais estável da costa recifense, não revelando sinais de erosão, além de se constituir em trecho de grande acúmulo de sedimentos.

Setor 5 - em virtude das obras de recuperação da orla de Brasília Teimosa, em 2004, tornou-se possível a identificação desse quinto setor, também pertencente ao litoral do Recife, cuja extensão é da ordem de $1,3 \mathrm{~km}$, que apresenta como principais características a ausência de pós-praia e a presença de uma linha contínua de recifes paralela à costa e situada muito próximo à praia, que serviu de suporte para a construção de 1.000 metros de muro de contenção em concreto armado, com a finalidade de assegurar a estabilidade da linha de costa. A presença de praia nesse setor resume-se a uma faixa de 300 metros situada no extremo norte, na localidade denominada de "Buraco da Velha".

\section{Praia de Boa Viagem}

A Praia de Boa Viagem, área de desenvolvimento deste estudo, insere-se no setor médio da planície costeira de Pernambuco, ocupando sua porção mais externa, apresentando-se como uma faixa arenosa com aproximadamente 8,0 quilômetros de extensão, praticamente retilínea. Limita-se ao sul pelas coordenadas $08^{\circ} 08^{\prime} 55^{\prime \prime}$ de latitude S e $34^{\circ} 54^{\prime} 24^{\prime \prime}$ de longitude $\mathrm{W}$, e ao norte pelas coordenadas $08^{\circ} 06^{\prime} 06^{\prime \prime}$ de latitude S e 34 53'04" de longitude W.

A planície costeira dessa faixa de praia constitui-se de uma grande variedade de depósitos sedimentares, resultantes da interação de diversos agentes, tais como as flutuações do nível relativo do mar e os processos dinâmicos costeiros. A evolução dessa Planície Costeira evidencia-se pela presença de dois registros sedimentares, os "Terraços Marinhos Pleistocênicos" e os "Terraços Marinhos Holocênicos".

\section{PROCESSOS METODOLÓGICOS}

Os procedimentos adotados para a produção deste trabalho de pesquisa desenvolveram-se em três etapas.

A primeira etapa consistiu em identificar e caracterizar a área de estudo por meio da investigação bibliográfica de trabalhos pretéritos, de cunho geológico, geográfico e de engenharia costeira, bem como de relatórios e projetos desenvolvidos para a área selecionada.

A segunda etapa realizou-se por meio do monitoramento e levantamento de dados, pelos quais se desenvolveram o registro e o acompanhamento de dados hidrodinâmicos apresentados por institutos de pesquisa para a região de estudo, bem como pela realização simultânea dos trabalhos de campo, com levantamento e coleta de dados de campo (hidrológicos e morfológicos) realizados na área costeira selecionada.

Finalmente, coube à terceira e última etapa a análise e interpretação dos estudos realizados, pelos quais, associados à avaliação das intervenções costeiras inseridas nas respectivas áreas de estudo, fundamentou-se a conclusão deste trabalho. 


\section{MONITORAMENTO E LEVANTAMENTO DE DADOS}

\section{Monitoramento de dados hidrodinâmicos}

Durante o período de um ano, entre os meses de setembro/2009 e agosto/2010, realizou-se para a área litorânea em estudo o monitoramento e o registro das previsões de dados de ventos (velocidade e direção) e de ondas (altura significativa, período de pico e direção), apresentados pelo Modelo WWATCH GLOBAL do Centro de Previsão de Tempo e Estudos Climáticos (CPTEC/ INPE), e pelos Modelos NCEP e ATLASUL do Sistema de Previsão de Ondas (SPO) da Universidade Federal do Rio de Janeiro (UFRJ).

\section{Dados monitorados}

. Velocidade e direção dos ventos

O comportamento da velocidade e da direção dos ventos atuante na área costeira em estudo obteve-se pelo registro dos espectros de ondas (Figura 5), disponibilizados pelo Sistema de Previsão de Ondas (SPO/UFRJ).

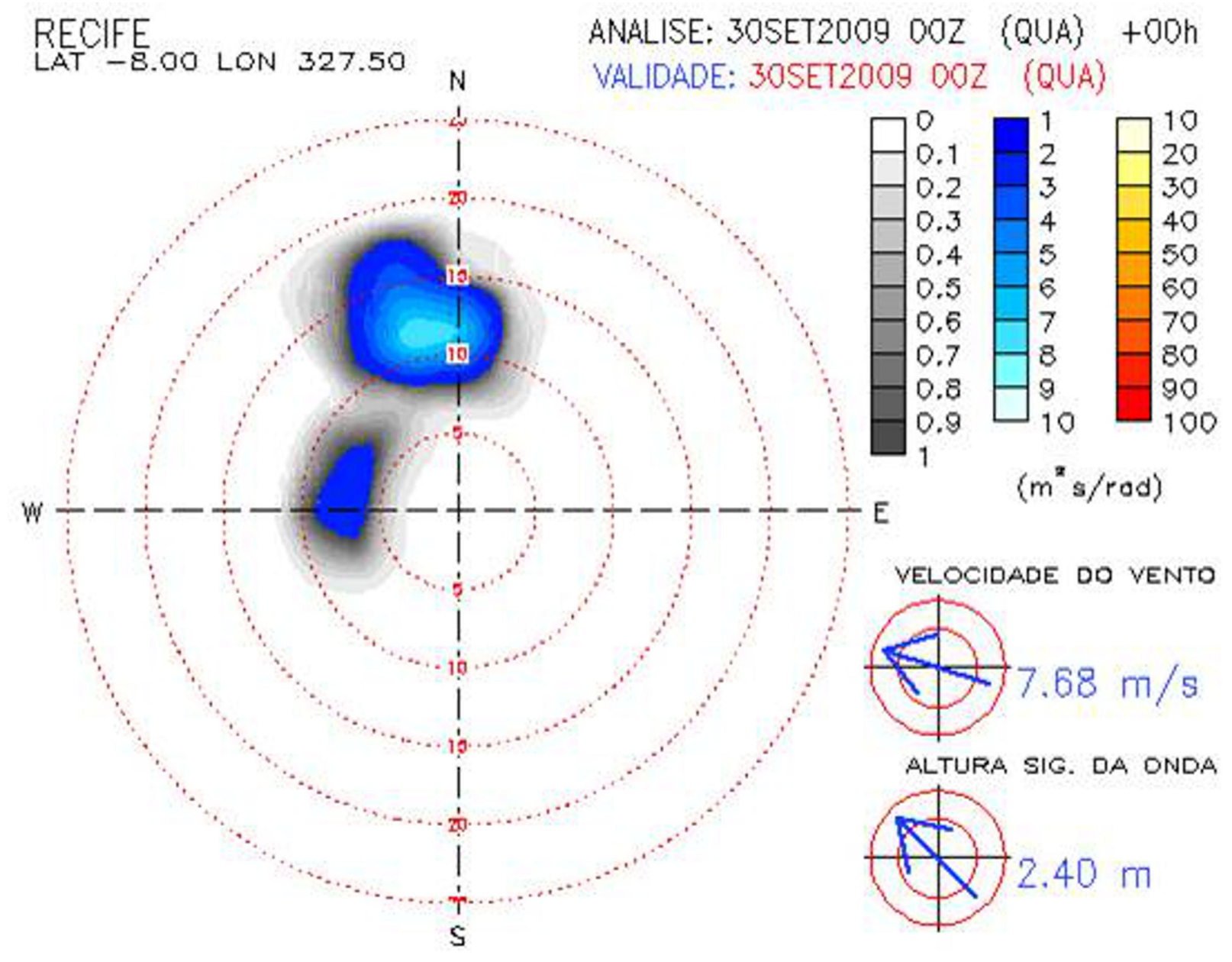

Figura 5 - Modelo de espectro monitorado para a área de estudo Fonte: SPO/UFRJ (2009)

A caracterização do regime de ventos predominantes é essencial para a melhor compreensão dos processos evolutivos do litoral, favorecendo, também, a identificação do tipo de ondas predominantes na costa. 
Com o registro dos espectros de ondas, foi possível, então, a elaboração dos histogramas de velocidades dos ventos (Figura 6) e do histograma de direção dos ventos, atuantes na costa em estudo, no período de setembro/2009 a agosto/2010.

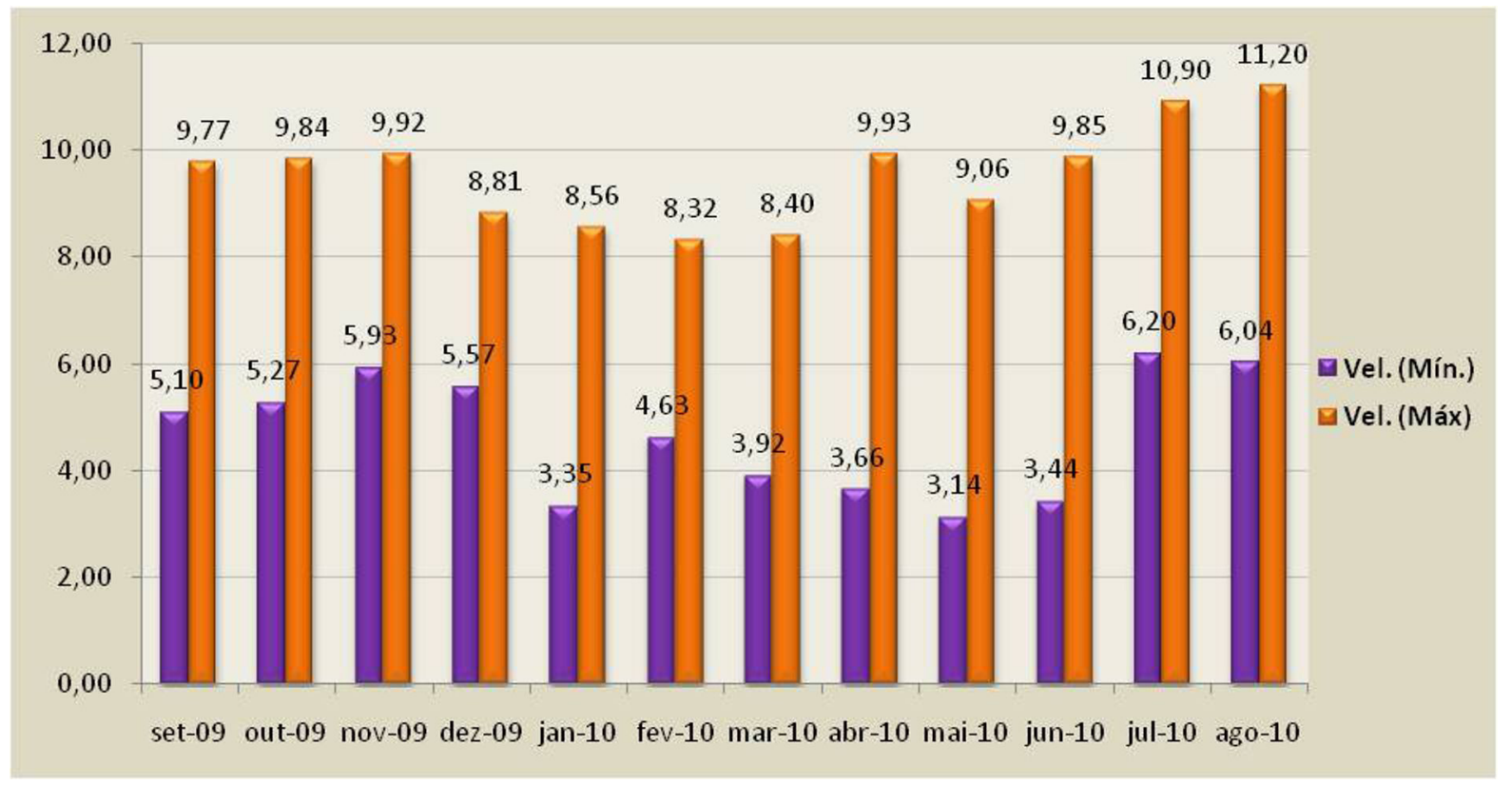

Figura 6 - Velocidades dos ventos (m/s) monitoradas no período de set./2009 a ago./2010. Fonte: Gois (2011)

Durante os doze meses de monitoramento, a velocidade do vento oscilou entre 3,14 m/s e 11,2 $\mathrm{m} / \mathrm{s}$, período em que predominaram majoritariamente os ventos E-SE.

Nos meses de julho e agosto, foi possível identificar uma intensificação no comportamento da velocidade dos ventos atuantes na costa, com registro de velocidades máximas acima de $10,0 \mathrm{~m} / \mathrm{s}$ e velocidades médias mensais ultrapassando a marca de $8,8 \mathrm{~m} / \mathrm{s}$. Nesse período prevaleceram os ventos $\mathrm{SE}$ e E-SE, com ligeiro predomínio dos ventos E-SE.

Entre janeiro e maio, os ventos apresentaram-se mais amenos, com médias de velocidades mensais inferiores a $6,8 \mathrm{~m} / \mathrm{s}$. Nesses meses predominaram os ventos E-SE, à exceção de janeiro, quando prevaleceram os ventos $\mathrm{E}$.

No período de monitoramento, predominaram os ventos E-SE, com ocorrência de aproximadamente $60 \%$, seguidos de $18 \%$ de ventos E e 14\% de ventos SE (Figura 7).

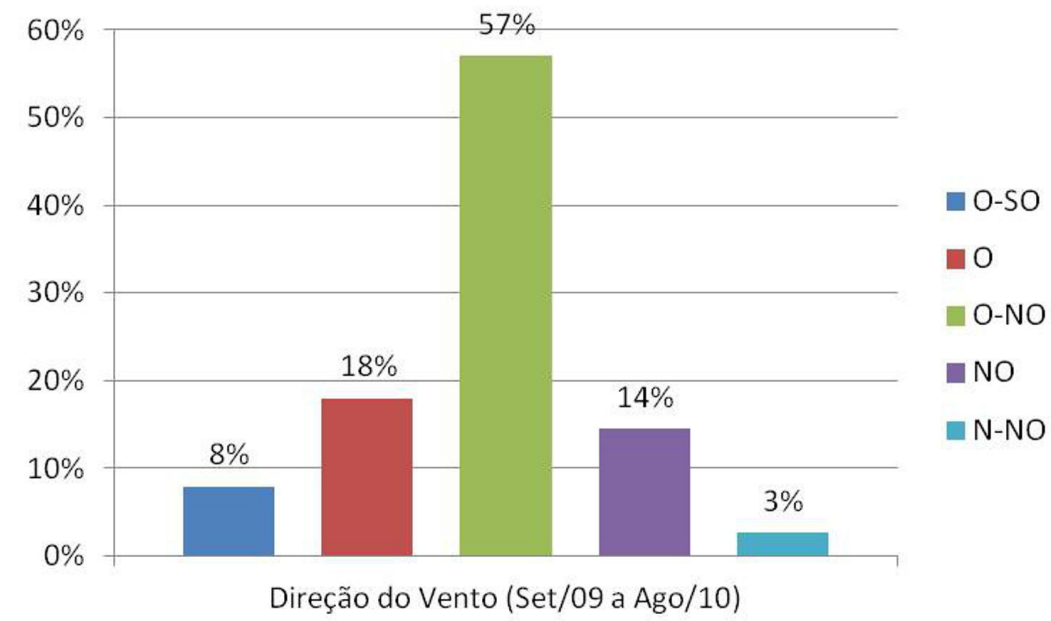

Figura 7 - Histograma de direção dos ventos atuantes monitorada no período de set./2009 a ago./2010 Fonte: Modificada de Gois (2011) 
Esses resultados se mostraram compatíveis com medições realizadas por Manso (1995), na Praia de Boa Viagem, entre os meses de setembro de 1994 e dezembro de 1995, quando se observou a predominância de ventos E-SE, cerca de 70\% do grupo de amostras registradas, e com um percentual menor, na ordem de $15 \%$ das amostras, os ventos de E.

\section{. Altura significativa de onda}

A altura significativa de onda (Hs) corresponde à média das alturas da terça parte das ondas mais altas. A identificação dos valores máximos de ondas é instrumento fundamental para a definição e avaliação de estruturas de proteção costeira.

As alturas significativas de onda apresentadas pelo espectro de ondas no período de setembro/2009 a agosto/2010 possibilitaram a elaboração dos histogramas de comportamento das alturas (mínima/máxima e média) para um ciclo de 12 meses (Figura 8).

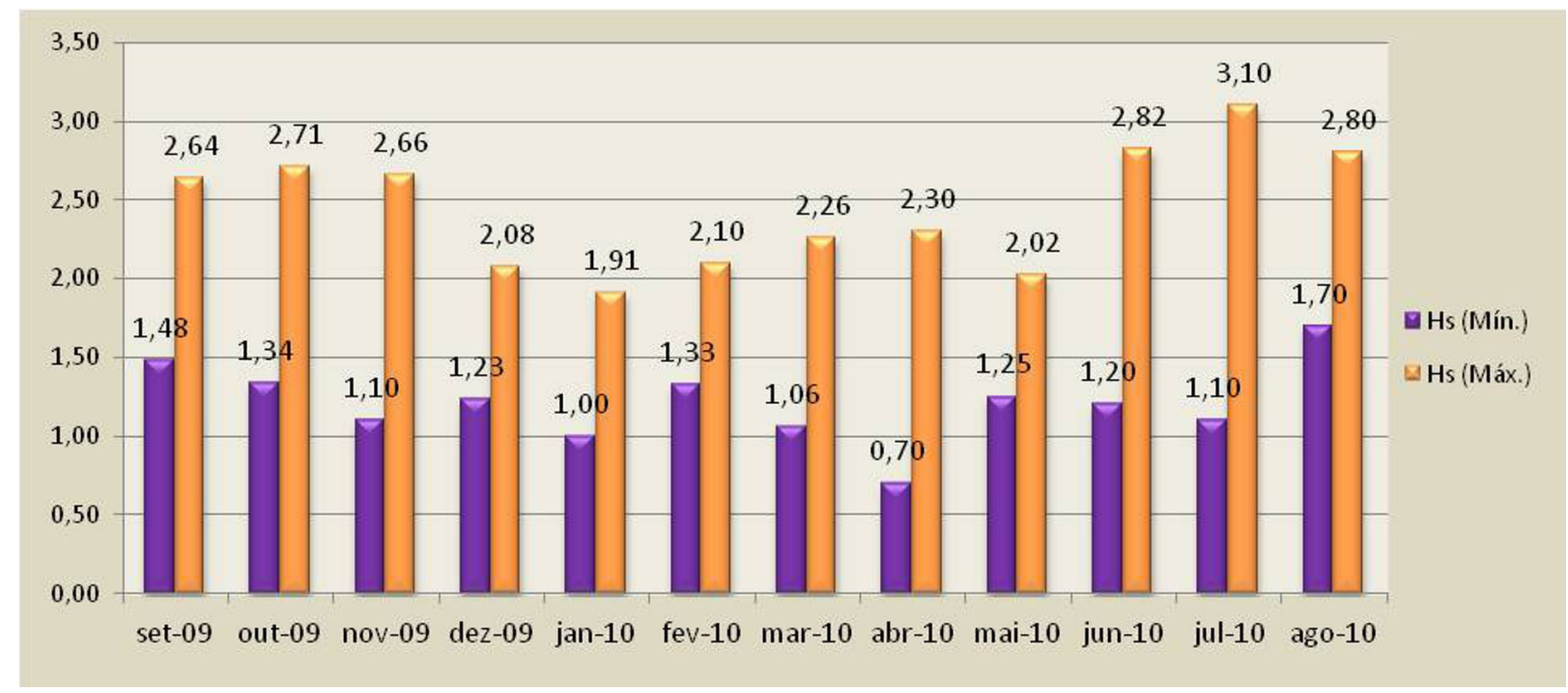

Figura 8 - Altura significativa de onda (m) monitorada no período de setembro/2009 a agosto/2010 Fonte: Gois (2011)

O monitoramento revelou que o clima de ondas para a área costeira em estudo apresenta um comportamento típico das duas estações climáticas (verão e inverno) que caracterizam a região. Durante todo o período de monitoramento, a altura significativa $(\mathrm{Hs})$ variou entre 0,70 e 3,10 m, tendo-se observado uma expressiva elevação nas alturas no período de inverno, sobretudo nos meses de junho, julho e agosto, quando se registraram alturas superiores a 2,80 m e alturas médias superiores a 2,00 m. Em contrapartida, verificou-se que durante o verão, a média das alturas significativas de onda oscilou entre 1,52 m e 1,69 m, com alturas máximas não excedendo a marca de 2,30 m.

. Período de pico das ondas

A identificação do período de onda é imprescindível para a caracterização do regime de ondas de uma região e, consequentemente, de sua dinâmica costeira. A ocorrência de grandes períodos de pico em locais em que não há a presença de ventos fortes, por exemplo, pode indicar a predominância de marulhos longos.

O registro e a análise dos oceanogramas apresentados pelo Sistema de Previsões Oceânicas do CPTEC/INPE - Modelo WWATCH Global permitiu identificar o comportamento dos períodos de pico das ondas incidentes na área costeira em estudo entre setembro/2009 e agosto/2010, e elaborar os respectivos histogramas (Figura 9). 


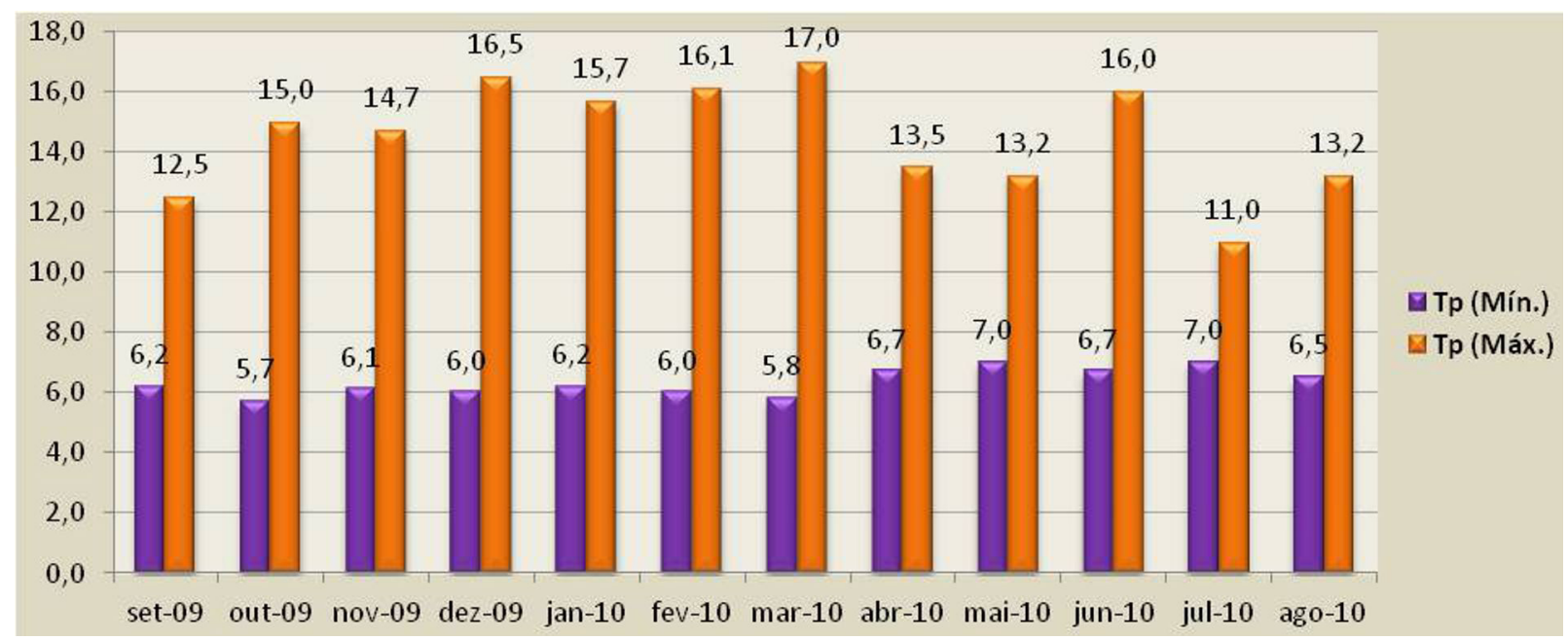

Figura 9 - Período de pico (s) mensal, monitorado no período de setembro/2009 a agosto/2010. Fonte: Gois (2011)

A avaliação do histograma revelou que, durante os meses de monitoramento, o período de pico das ondas oscilou entre 5,7 e 17,0 segundos. Essa variação é um forte indicativo de que a região se submete a dois tipos de ondas

As ondas de menores períodos são típicas das ondas do tipo sea, formadas em áreas próximas à costa, sob a influência de ventos locais. Enquanto as ondas de maiores períodos são características das ondas do tipo swell, formadas mais distante da costa e submetidas a um regime de ventos diferentes dos ventos locais.

. Direção de propagação da onda

O comportamento da direção de onda incidente na área de estudo registrou-se mensalmente a partir dos espectros de ondas - SPO/UFRJ (Figura 5), por meio dos quais, observou-se que, durante o período monitorado, predominaram as ondas procedentes de E-SE, com 40\% de ocorrência, seguidas pelas ondas provenientes de SE, com $27 \%$ de registro, e de $16 \%$ das ondas procedentes de E (Quadro 1).

Quadro 1 - Direção de ondas na área de estudo, apresentadas pelos Espectros de Ondas - SPO/UFRJ

\begin{tabular}{|c|c|c|}
\hline \multicolumn{2}{|c|}{ DIREÇÃO } & REGISTROS \\
\hline E-SE & 89 & $40 \%$ \\
\hline SE & 60 & $27 \%$ \\
\hline E & 35 & $16 \%$ \\
\hline S-SE & 22 & $10 \%$ \\
\hline E-NE & 11 & $5 \%$ \\
\hline NE & 5 & $2 \%$ \\
\hline N-NE & 2 & $1 \%$ \\
\hline Leituras & 224,0 \\
\hline
\end{tabular}

Fonte: (SPO/UFRJ, 2009)

Os resultados obtidos com o monitoramento e o registro da direção de ondas se mostraram compatíveis com o comportamento da direção dos ventos, verificada durante o mesmo período, no qual prevaleceram, também, os ventos E-SE, tendo-se observado como diferencial apenas maior ocorrência de vento leste do que sudeste. 
. Hidrodinâmica

Os levantamentos necessários à caracterização da hidrodinâmica costeira (clima de ondas e correntes) realizaram-se por meio de dois levantamentos de campo, respectivamente nos meses de julho/2009 (Tabela 1) e abril/2010 (Tabela 2).

Tabela 1- Dados hidrodinâmicos da Praia de Boa Viagem coletados em julho/2009

\begin{tabular}{|c|c|c|c|}
\hline \multicolumn{2}{|l|}{ ONDA } & \multicolumn{2}{|c|}{ CORRENTE LITORÂNEA } \\
\hline Altura $(\mathrm{m})$ & 0,87 & \multirow{2}{*}{ Velocidade $(\mathrm{m} / \mathrm{s})$} & \multirow{2}{*}{0,14} \\
\hline Período (s) & 6,50 & & \\
\hline Ângulo de Incidência & 50 & \multirow{2}{*}{ Direção } & \multirow{2}{*}{ S-N } \\
\hline Tipo de Arrebentação & Mergulhante & & \\
\hline
\end{tabular}

Tabela 2 - Dados hidrodinâmicos da Praia de Boa Viagem coletados em abril/2010

\begin{tabular}{|c|c|c|c|}
\hline \multicolumn{2}{|l|}{ ONDA } & \multicolumn{2}{|c|}{ CORRENTE LITORÂNEA } \\
\hline Altura (m) & 0,82 & \multirow{2}{*}{ Velocidade $(\mathrm{m} / \mathrm{s})$} & \multirow{2}{*}{0,12} \\
\hline Período (s) & 6,80 & & \\
\hline Ângulo de Incidência & 50 & \multirow{2}{*}{ Direção } & \multirow{2}{*}{$\mathrm{S}-\mathrm{N}$} \\
\hline Tipo de Arrebentação & Mergulhante & & \\
\hline
\end{tabular}

O estudo comparativo dos resultados obtidos pelos levantamentos realizados em campo não apresentou mudanças significativas em relação ao padrão de comportamento de dados pretéritos da hidrodinâmica costeira da Praia de Boa Viagem.

As ondas identificadas nos levantamentos realizados apresentaram alturas médias de $0,87 \mathrm{~m}$ (julho/2009) e 0,82 m (abril/2010), com período médio de 6,5 e 6,8 segundos respectivamente.

Em razão da proximadade de resultados, e por terem sido desenvolvidos em meses de características climáticas bastante semelhantes, os dados obtidos para a hidrodinâmica da Praia de Boa Viagem mostraram-se bastante compatíveis com os estudos apresentados recentemente pelo Projeto MAI (2009), no qual se encontraram alturas médias de onda de 0,97 m (ago-out/2007) e 0,66 m (mai-jun/2008), e períodos significativos de 5,97 e 5,88 segundos respectivamente.

O tipo de onda "mergulhante", identificado nos levantamentos realizados, com pequeno ângulo de incidência, produz fracas correntes de deriva, o que implica reduzido transporte longitudinal de sedimento.

No entanto, diante dos dados coletados, foi possível estimar a quantidade de areia transportada pela deriva litorânea, cujo volume, obtido por meio da equação empírica de Komar, descrita a seguir, foi da ordem de 1.073,0 $\mathrm{m}^{3} /$ dia, o que representa um volume de $44,7 \mathrm{~m}^{3} /$ hora:

Equação Empírica de Komar:

Qs $=3,4(\mathrm{ECn}) \operatorname{sen}(\alpha) \cos (\alpha)$

em que, E (energia da onda na zona de arrebentação) é obtida pela relação:

$\mathrm{E}=1 / 8\left(\mathrm{pgH}^{2}\right)$ 
onde p (densidade da água do mar) tem valor igual a $1020 \mathrm{~kg} / \mathrm{m}^{3}$, e Cn (velocidade de grupo das ondas) é dado por meio da equação:

$\mathrm{Cn}=\sqrt{ } \mathrm{g}(2 \mathrm{H})$

Adotou-se o valor de H (altura de onda na zona de arrebentação) como a média dos valores obtidos nos levantamentos de campo (Tabelas 1 e 2), enquanto o valor para o ângulo de incidência da onda na zona de arrebentação foi de $\alpha=5^{\circ}$, uma vez que este se manteve constante durante os levantamentos realizados.

\section{. Sedimentologia}

Com o objetivo de identificar a distribuição textural dos sedimentos e suas relações com a declividade da praia e seu nível energético, coletaram-se amostras superficiais em cada uma das referidas praias pertencentes à área de estudo.

Em laboratório, estudaram-se as amostras segundo os métodos adotados pelo Laboratório de Geologia e Geofísica Marinha da Universidade Federal de Pernambuco (LGGM/UFPE). Inicialmente, levou-se o material coletado à estufa para secagem a uma temperatura de $60^{\circ} \mathrm{C}$. Em seguida, depois de quarteado, retiraram-se 100 gramas de cada amostra para efetuar o peneiramento úmido, por meio do qual, realiza-se a separação do sedimento em cascalho, areia e lama. Com a utilização de um conjunto de 6,0 peneiras, de malhas variando entre 1,0 e 4,0 $\varphi$ (phi), realizou-se a análise granulométrica e posterior classificação textural, conforme "Escala de Wentworth".

O estudo revelou uma grande uniformidade na composição e textura do material do estirâncio, apresentando uma predominância de areia fina. A distribuição geral dos sedimentos (Figura 10) mostra que $78,33 \%$ das amostras coletadas são compostas por areia fina, $13,33 \%$ de areia média e $8,33 \%$ de areia muito fina.

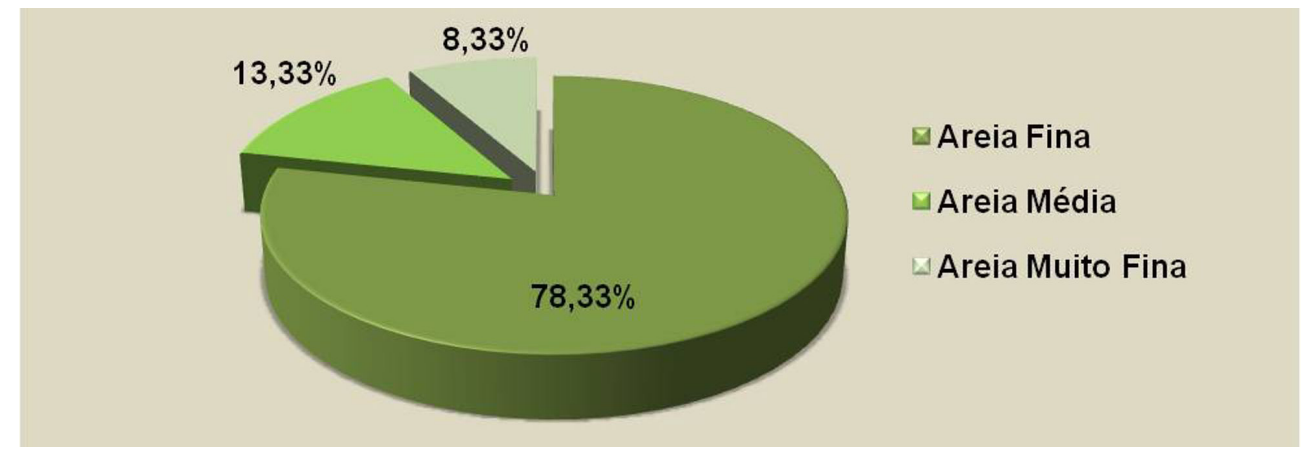

Figura 10 - Distribuição granulométrica dos sedimentos na praia de Boa Viagem, Recife-PE

\section{. Morfodinâmica praial}

O comportamento da morfologia praial e a relação existente entre esse ambiente e a dinâmica das ondas obtiveram-se com o levantamento de 20 perfis, posicionados em pontos sequenciais e espaçados a cada 100,0 m (Figura 11). 


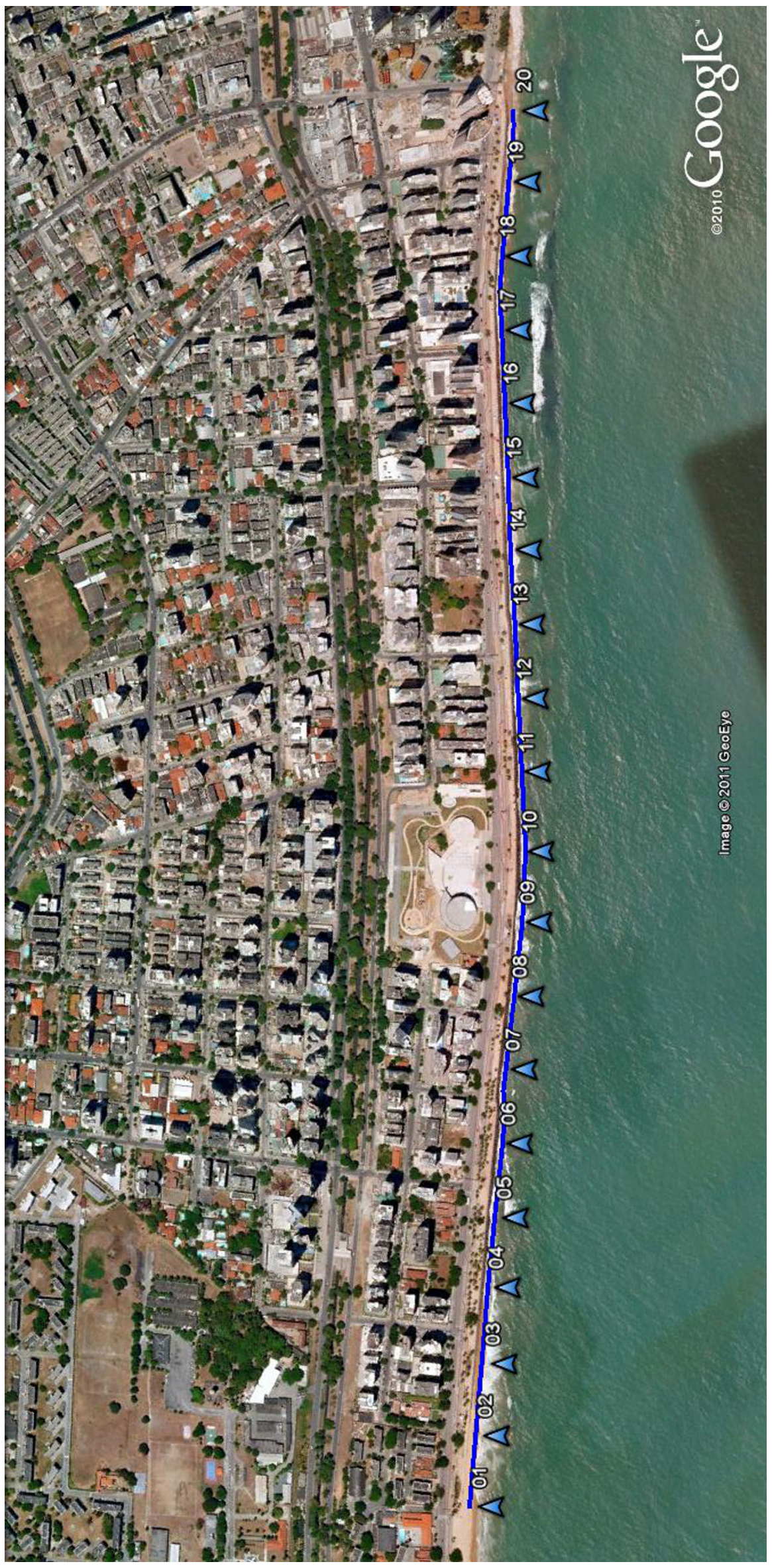

Figura 11 - Localização dos pontos de levantamento dos perfis, Praia de Boa Viagem, Recife-PE 
Os perfis morfodinâmicos realizaram-se por meio de nivelamento topográfico, pelo qual se determinaram as cotas dos pontos definidos sobre os perfis, locados em relação a um RN (Referência de Nível). Nos referidos pontos, realizaram-se três levantamentos (abril/2010, agosto/2010 e março/2011), representados graficamente (Figura 12), por meio dos quais os perfis levantados foram dispostos em superposição, de modo a propiciar a análise da variabilidade de comportamento do perfil praial em diferentes épocas e estações do ano.

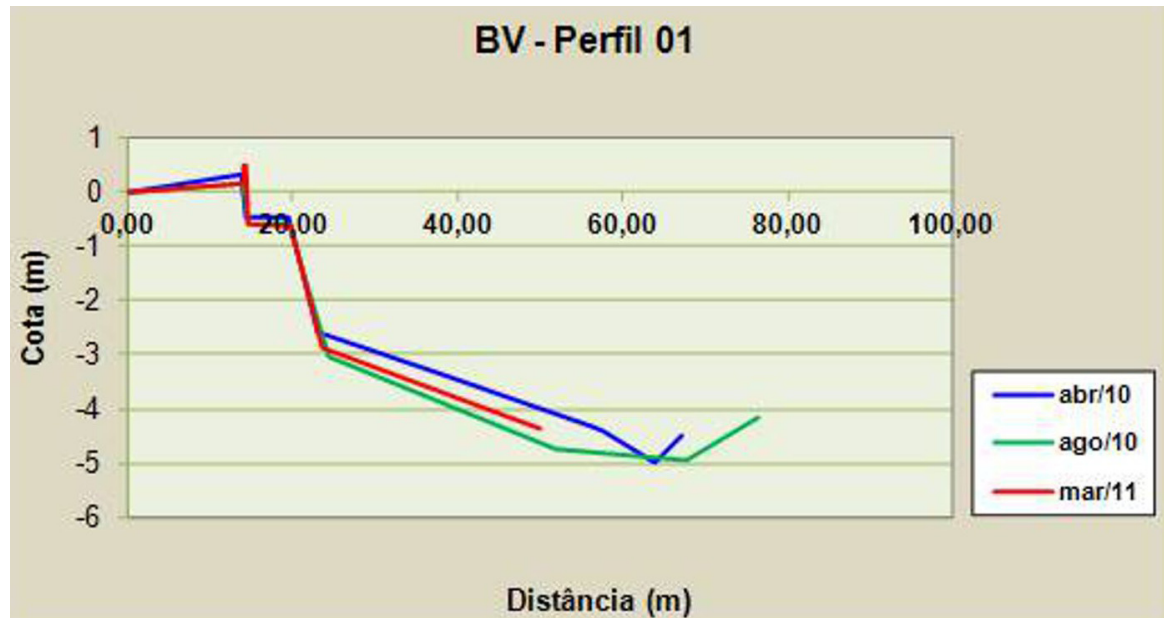

Figura 12 - Evolução dos perfis morfodinâmicos levantados na Praia de Boa Viagem (Perfil 01) Fonte: Modificada de Gois (2011)

A análise da evolução dos perfis levantados revelou que, em razão da quantidade de material sedimentar depositado no perfil (face da praia), principalmente na zona de estirâncio, os perfis morfodinâmicos apresentaram alturas e comprimentos distintos, permitindo identificar e classificar a morfodinâmica praial em três setores bem individualizados, de acordo com a inclinação de cada perfil.

. Setor de baixa inclinação $(i<10 \%)$ - os perfis com baixa inclinação $(50 \%)$ apresentaram perfil praial plano, em função de um significativo aporte sedimentar.

. Setor de média inclinação $(10<\mathrm{i}<20 \%)$ - os perfis de média inclinação (40\%) apresentaram perfil praial relativamente plano, com aporte de sedimento menos significativo, porém ainda presente.

. Setor de alta inclinação (i > 20\%) - os perfis de alta inclinação (10\%) apresentaram perfil praial inclinado, principalmente em razão de um processo muito incipiente de sedimentação (Figura 13).

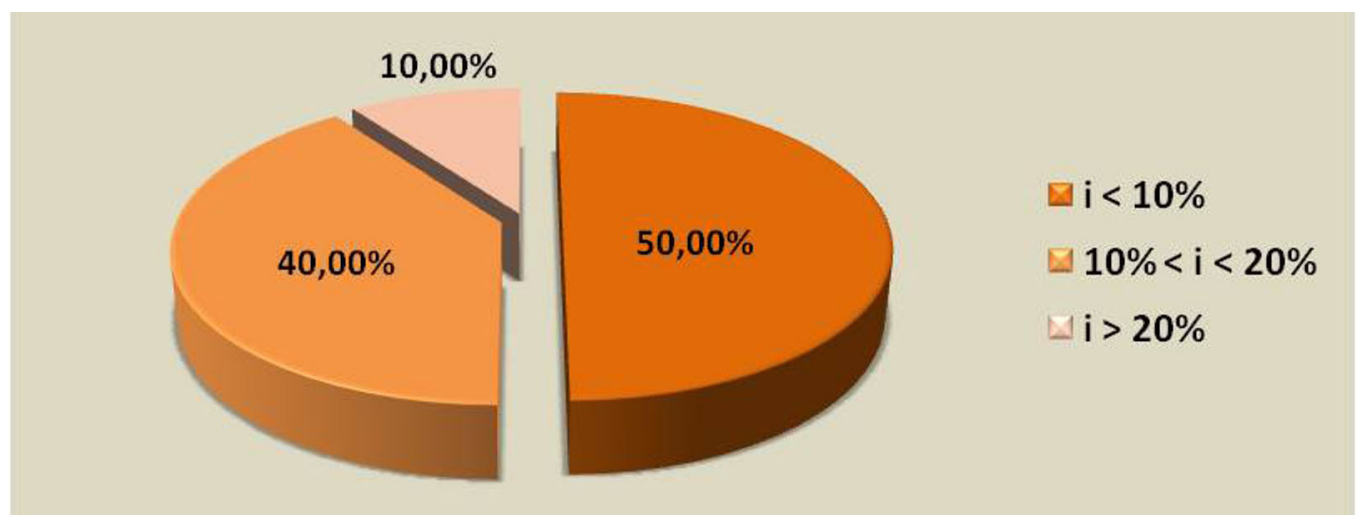

Figura 13 - Percentual de ocorrência dos perfis morfodinâmicos da Praia de Boa Viagem quanto à inclinação Fonte: Gois (2011) 
Observou-se, ainda, que o comportamento dos perfis morfodinâmicos esteve diretamente relacionado com a intensidade da energia na costa, tendo-se identificado que, durante o inverno, período de maior intensidade dos ventos e de ocorrências das maiores ressacas, os perfis morfodinâmicos, de forma geral, sofreram rebaixamento. Em contrapartida, no verão, esses perfis foram gradativamente recompostos.

\section{. Levantamento batimétrico}

Com o objetivo de identificar as principais características morfológicas da área de estudo, realizou-se o levantamento batimétrio da plataforma continental interna adjacente à Praia de Boa Viagem, representado graficamente pelo mapa batimétrico (Figura 14), apresentando curvas de nível com equidistâncias de 1,0 m, no qual se observa uma plataforma homogênea, apresentando pouca declividade, que apenas se destaca pela presença de um canal pouco profundo, de fundo plano em toda sua extensão, com largura média de 648,0 m.

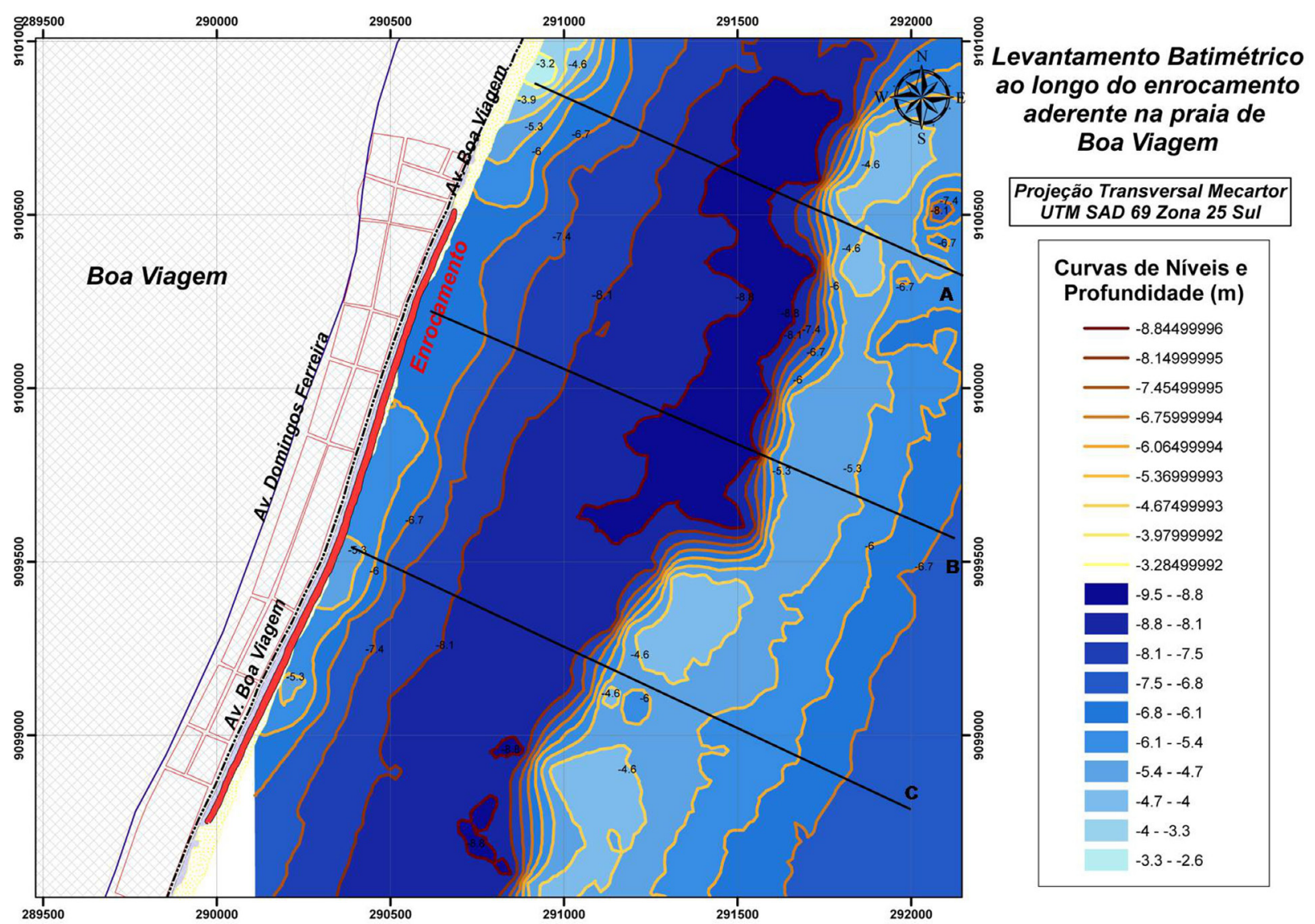

Figura 14 - Mapa batimétrico da plataforma continental adjacente da praia de Boa Viagem, Recife/PE

O canal identificado pelo mapa batimétrico está disposto paralelamente à linha de praia, apresentando flancos suaves, com declividade de $2,8 \%$ na margem esquerda, e um pouco mais íngreme na margem direita, com declividade de 5,0\%, coincidindo em toda a sua extensão com a presença de uma estrutura recifal submersa.

A maior largura desse canal encontra-se na sua porção norte e se delimita pela isobatimétrica de $-8,0 \mathrm{~m}$. O referido canal está disposto paralelamente à linha de praia, apresentando flancos suaves, com declividade de $2,8 \%$ na margem esquerda, e um pouco mais íngreme na margem direita, com declividade de $5,0 \%$, coincidindo em toda a sua extensão com a existência de um grande recife algálico. 
A análise do mapa revelou uma variabilidade nas isóbatas na área mais próxima à praia, decorrentes, provavelmente, da existência de falhas na construção recifal que se situa paralela à linha de praia. Observou-se, ainda, a redução das isóbatas em direção aos extremos da área de estudo, fato esse que, associado à existência de uma praia pouco desenvolvida, indica maior vulnerabilidade da parte central aos processos erosivos, área em que se encontra a estrutura de defesa costeira.

\section{RESULTADOS E DISCUSSÕES}

Os estudos desenvolvidos para a Praia de Boa Viagem permitiram identificar as principais causas indutoras dos processos erosivos naquela praia, bem como a relação que foi estabelecida, há aproximadamente duas décadas, entre a praia, o estado erosivo instalado e a estrutura de defesa costeira ali inserida.

\section{A erosão da Praia de Boa Viagem}

Sem desconsiderar a interferência dos fenômenos ambientais de ordem global, foi possível identificar que o processo erosivo da Praia de Boa Viagem sofreu a interferência direta e determinante de dois agentes: a antropização do ambiente praial, e a interferência da linha de recifes ao longo de quase toda a orla de Boa Viagem.

\section{A antropização do ambiente praial}

Embora o processo de antropização da Praia de Boa Viagem não se restrinja exclusivamente a uma ação particularizada, uma intervenção desempenhou um papel fundamental como agente indutor do processo de erosão naquela praia. Trata-se da obra de alargamento da Avenida Boa Viagem que, executada ao fim da década de 1980, expandiu a área urbanizada e proporcionou o avanço do calçadão em direção à praia, ocupando a faixa de pós-praia.

A ocupação e, consecutivamente, a impermeabilização da faixa de pós-praia suprimiram esse setor e, consequentemente, eliminaram a capacidade da praia em dissipar a energia incidente, bem como a possibilidade de troca e o abastecimento de areia, sobretudo durante as ressacas, sentenciando, dessa forma, a praia ao déficit sedimentar, por conseguinte, à instalação da erosão (Figura 15, A e B).
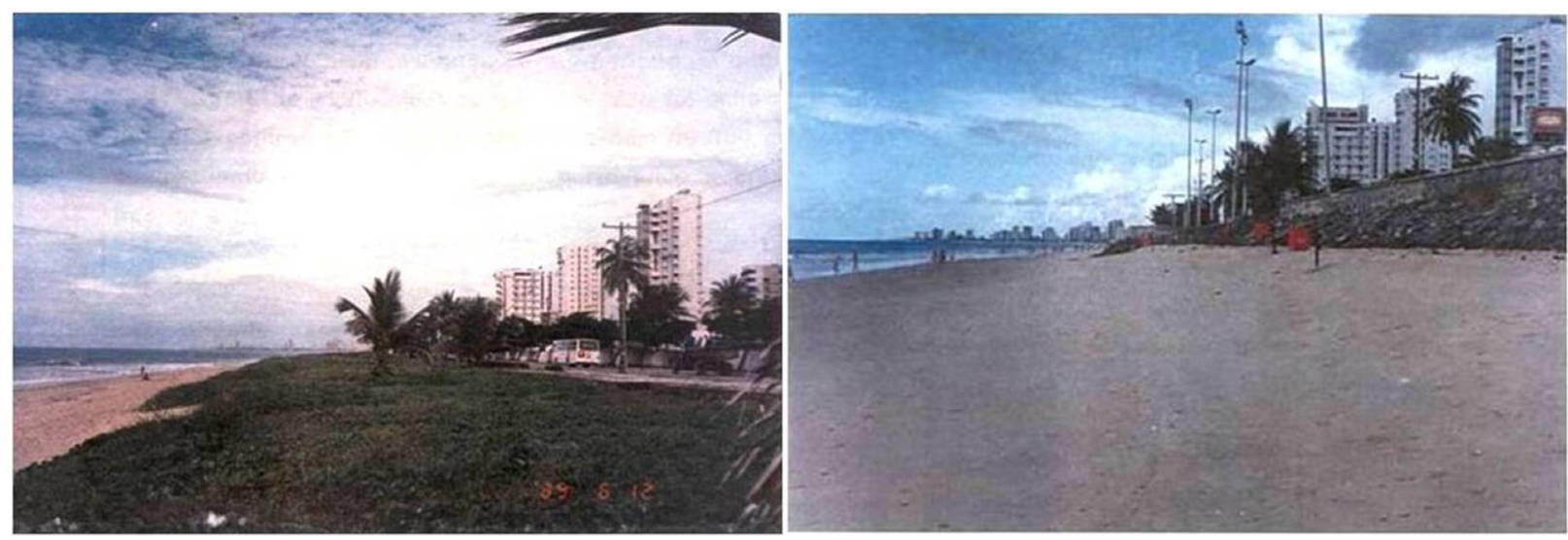

Figura 15 - Expansão da urbanização ocupou a faixa de pós-praia e sentenciou a área à erosão Fonte: Acervo do professor Manso, 1989 


\section{A interferência da linha de recifes}

Construções recifais paralelas à praia podem desempenhar um papel de proteção natural da costa, eliminando ou minimizando a incidência direta das ondas. No entanto, a ocorrência de falhas (descontinuidades) em uma linha de recifes paralela à praia, poderá representar a ocorrência de mudanças no comportamento da linha de costa, provocadas pelo redirecionamento da energia das ondas incidentes. Pois, ao passar por uma abertura em um anteparo ou barreira, as ondas tendem a difratarem-se, formando um feixe divergente.

No caso de uma construção recifal, ao passar pela abertura (falha), as ondas difratadas têm sua energia redirecionadas para vários pontos da costa. Com a ocorrência de mais de uma abertura (falha) na linha de recifes, as ondas difratadas tendem a interagir umas com as outras em diversos pontos, amplificando suas energias e, consequentemente, aumentando a quantidade de pontos e a intensidade com que atingem a costa (Figura 16, A e B).

A
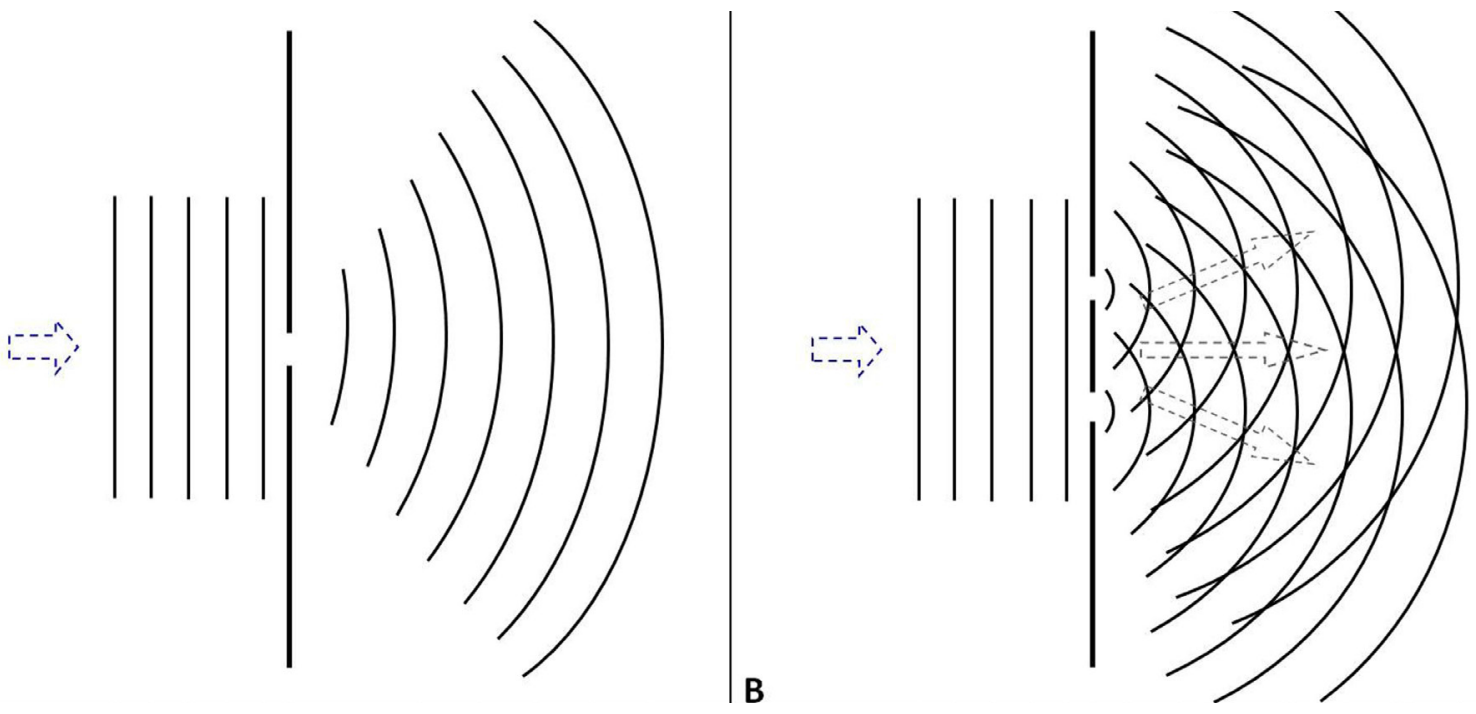

Figura 16 - Processo de difração de ondas diante da ocorrência de uma ou mais aberturas em construções recifais

O processo de difração das ondas leva a existência de construções recifais a responder diretamente pelo comportamento da geometria da linha de praia adjacente. Quando a linha de recifes é contínua, a faixa de praia cresce em direção à barreira e apresenta uma tendência de formação de um tômbolo (cúspide), no entanto, quando ocorrem falhas, a tendência é de formação de um embaiamento (enseada) na faixa de praia, em razão da concentração de energia (Figura17). 
GOIS, L. A.; OLIVEIRA, N. M. G. A.; MANSO, V. A. V.
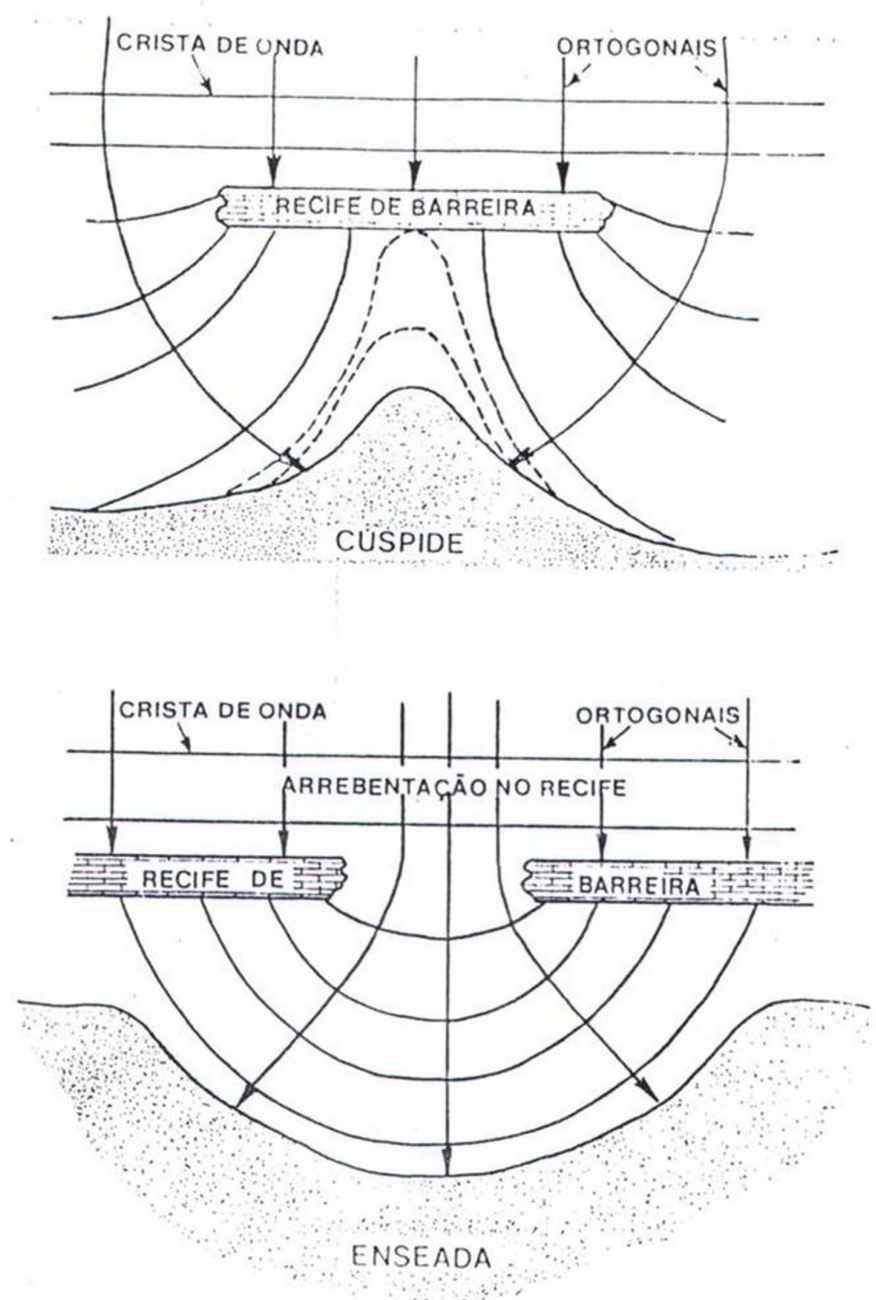

Figura 17 - Efeitos das ondas sobre linhas de recifes Fonte: Manso et al. (1995)

No caso da Praia de Boa Viagem, observou-se que os dois principais eventos erosivos, que culminaram com a destruição parcial da urbanização, respectivamente em 1994 e 2008, apresentaram nos pontos mais atingidos pela erosão descontinuidades da linha de recifes paralela à praia (Figuras 18 e 19).

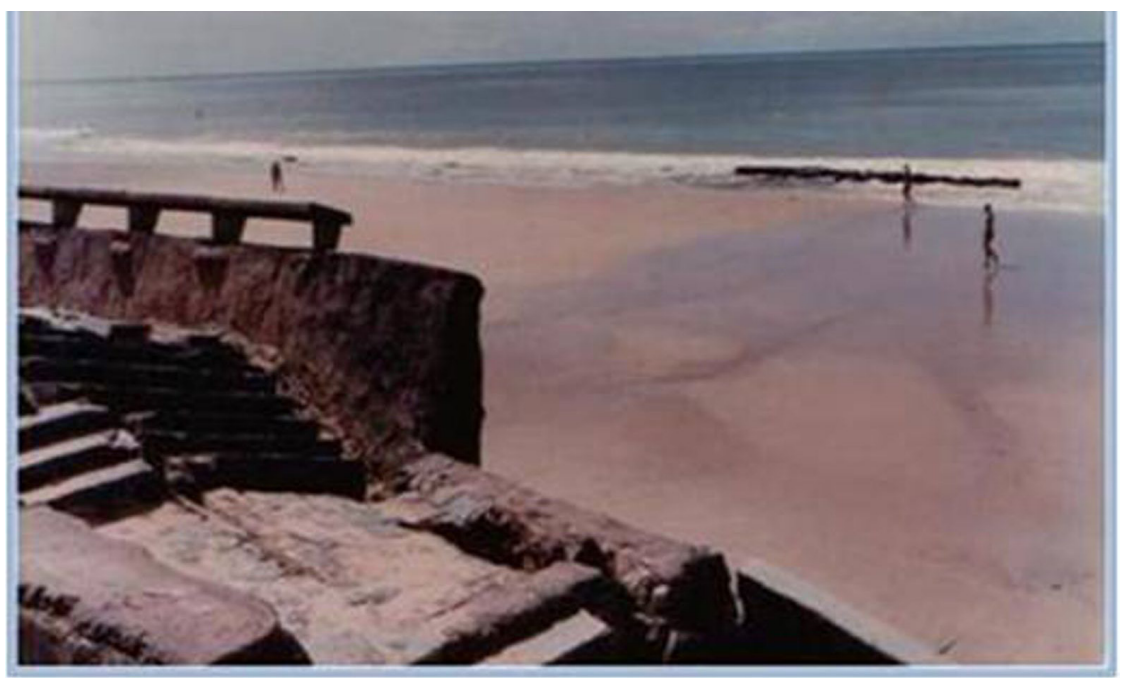

Figura 18 - Local de instalação de processo erosivo na Praia de Boa Viagem em 1994 nas proximidades do Hotel Atlante Plaza 


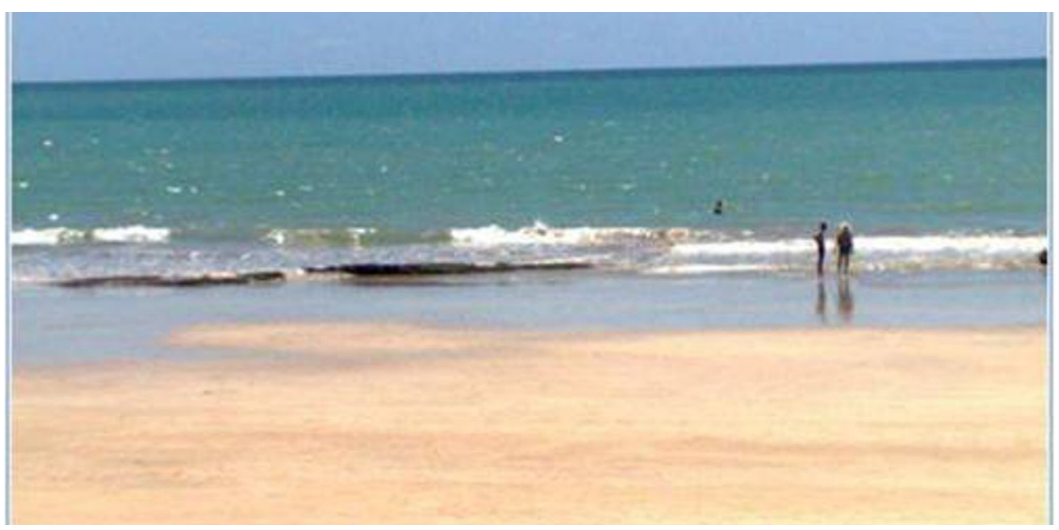

Figura 19 - Local de instalação de processo erosivo na Praia de Boa Viagem em 2008, nas proximidades da Rua Coronel Sérgio Henrique Cardim

Imagens aéreas do trecho atingido mais recentemente na Praia de Boa Viagem, especificamente em 2008, evidenciam a grande quantidade de descontinuidades da linha de recifes. Essas descontinuidades proporcionaram o desencadeamento do fenômeno de difração das ondas, que pode ser facilmente percebido pelas marcas registradas na "zona de espraiamento" (Figura 20).

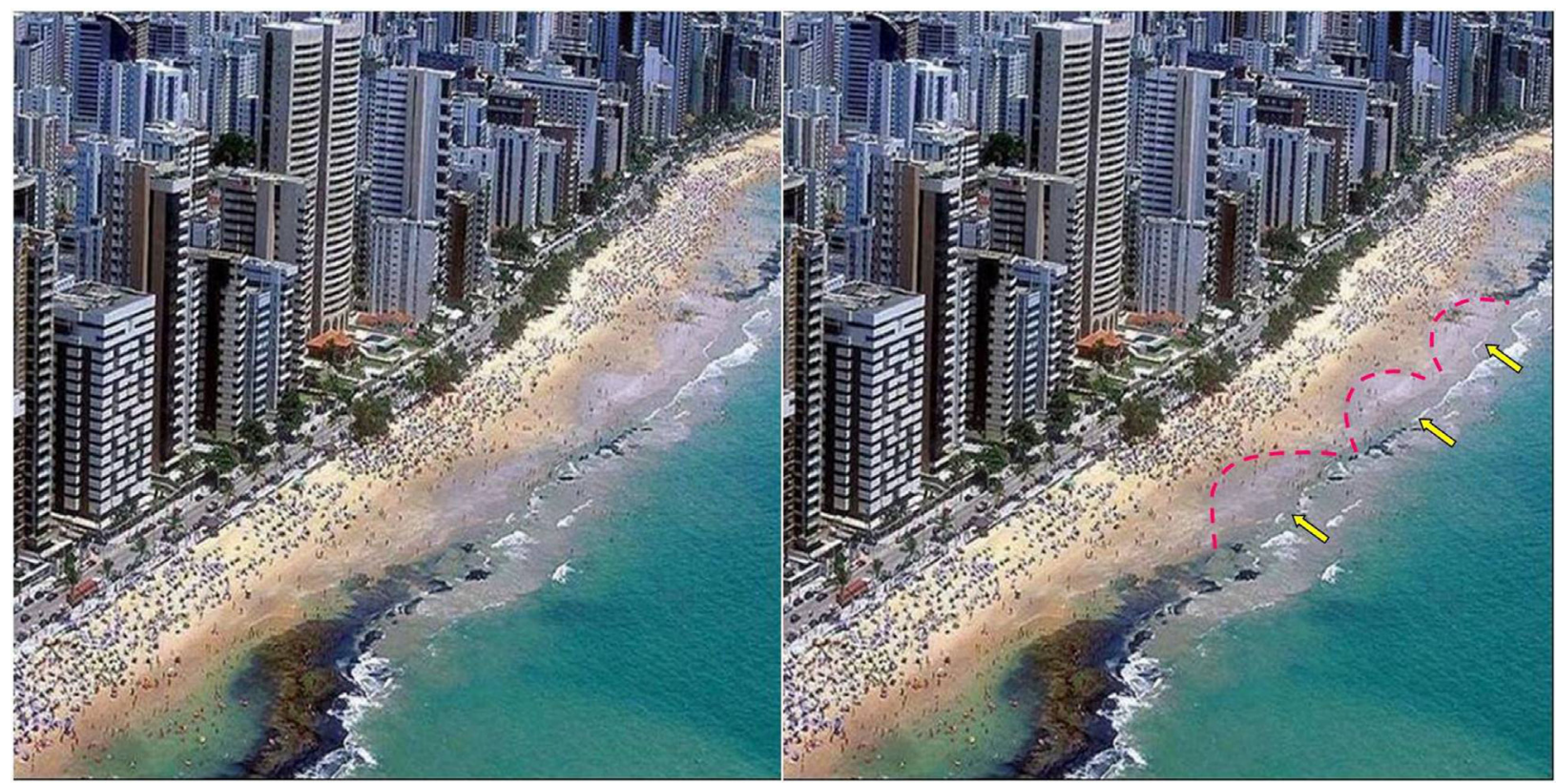

Figura 20 - Vista aérea da área atingida pelo processo erosivo ocorrido na Praia de Boa Viagem em 2008

O processo erosivo que se instalou nesse trecho da Praia de Boa Viagem reflete significativamente a forte influência da morfologia dos recifes na linha de costa, principalmente em razão da proximidade do recife à praia e da magnitude das descontinuidades existentes nas linhas de recifes.

\section{A estrutura de proteção costeira}

Embora a estrutura de enrocamento aderente, implantada desde 1996 e ampliada em 2010, venha proporcionando a preservação de aproximadamente $2,5 \mathrm{~km}$ da área de costa urbanizada, não se tem observado, desde então, nenhuma mudança, ou mesmo indício, que represente a recomposição dos perfis de praia e aponte para a recuperação do ambiente praial. Por conseguinte, ainda que essa estrutura tenha proporcionado com êxito a estabilização da linha no trecho atingido pelo processo de erosão, deve-se salientar que ela não eliminou a necessidade de uma nova intervenção com a finalidade de recuperar esse segmento litorâneo. 


\section{CONSIDERAÇÕES FINAIS}

Baseado nos estudos desenvolvidos e na análise de dados pretéritos, alicerçados pelos resultados aqui apresentados, conclui-se que o processo de erosão que atingiu a Praia de Boa Viagem deu-se, fundamentalmente, em razão da grande quantidade de falhas (aberturas) existentes na linha de recifes que, muito próxima à costa, proporcionou o direcionamento e a canalização dos esforços das ondas incidentes para diversos pontos da costa, impondo à praia, por meio do processo de difração das ondas, um excesso de energia capaz de remover o suprimento de sedimentos da praia.

Evidenciou-se, também, que a supressão da faixa de pós-praia representou uma contribuição significativa para a instalação da erosão, uma vez que esse setor, além de exercer uma função dissipadora das energias incidentes na costa, representa uma importante área de acúmulo de sedimentos, que, muitas vezes, responde pelo equilíbrio sedimentar da praia.

Quanto ao controle da erosão e à estabilização da linha de costa, conclui-se que o enrocamento aderente cumpre satisfatoriamente a preservação e proteção de todo o patrimônio que se encontra à sua retaguarda. No entanto, em razão do enorme valor turístico e ambiental que representa a Praia de Boa Viagem, mas especialmente pela necessidade de recuperação do ambiente praial e de, consequentemente, devolver o equilíbrio a esse ecossistema, faz-se necessária a implantação de intervenções complementares no sentido de recomposição da pós-praia.

Considerando que, passados aproximadamente quinze anos da implantação do enrocamento aderente, não se registraram resultados significativos na recomposição natural do perfil de praia, torna-se recomendável a reconstituição do setor de pós-praia por meio de engordamento artificial. No entanto, com o propósito de não ampliar as probabilidades de insucesso que comumente permeiam esse tipo de intervenção, faz-se necessária, antes da implantação do engordamento artificial, a adoção de procedimentos específicos à Praia de Boa Viagem, tais como a obturação das aberturas existentes na linha de recifes, eliminando o processo de difração das ondas; e ainda, em razão da fragilidade do litoral e da possibilidade de ocorrência de eventos pontuais e extemporâneos, de alta energia, capazes de provocar um estado erosivo de grande magnitude, a implantação de um perfil de praia que se sobreponha à estrutura de proteção aderente, preservando a estabilização da linha de costa em sua atual posição e, consequentemente, a proteção às áreas de urbanização e lazer situadas à sua retaguarda.

\section{REFERÊNCIA BIBLIOGRÁFICA}

BARBOSA, José Antônio; LIMA FILHO, Mário. Aspectos estruturais e estratigráficos da faixa costeira Recife, Natal: observações em dados de poços. Boletim de Geociências da Petrobras, Rio de Janeiro, v. 14, n. 2, p. 287-304, 2006. ISSN: 0102-9304. Disponível em: <http://vdpf.petrobras.com.br/vdpf/todasEdicoes. do $>$. Acesso em: 17 jan. 2013.

COUTINHO, Paulo da Nóbrega. Geologia marinha da plataforma continental Alagoas- Sergipe. Recife. 1976. 119 p. Tese (Livre Docência) - Universidade Federal de Pernambuco, 1976.

DOMINGUEZ, José Maria Landim et al. Geologia do quaternário costeiro do estado de Pernambuco. Revista Brasileira de Geociências, São Paulo, v. 20, n. 1-4, p. 208-215, mar./abr. 1990. ISSN: 0375-7563.

GOIS, Luis Augusto de. Avaliação das opções de proteção costeira: praia de Boa Viagem, Recife-PE e praia de Bairro Novo, Olinda-PE. 2011. Dissertação (Mestrado em Tecnologia Ambiental) - Instituto de Tecnologia de Pernambuco, Recife, 2011.

INSTITUTO BRASILEIRO DE GEOGRAFIA E ESTATÍSTICA (IBGE). Censo demográfico 2010. Rio de Janeiro, 2011.

KÖPPEN, W. Climatologia: com um estúdio de los climas de la tierra. New Jersey: Laboratory of Climatology, 1948.

MANSO, Valdir do Amaral Vaz et al. Estudo da erosão costeira na praia de Boa Viagem: relatório técnico. Recife: Prefeitura da Cidade do Recife, 1995. 
MANSO, Valdir do Amaral Vaz; CORRÊA, Iran. C. S.; GUERRA, Núbia C. Morfologia e sedimentologia da plataforma continental interna entre as praias Porto de Galinhas e Campos, litoral sul de Pernambuco, Brasil. Pesquisas em Geociências, Porto Alegre, v. 30, n. 2, p. p. 17-25, 2003. ISSN 1518-2398.

MUEHE, Diete. O litoral brasileiro e sua compartimentação. In: CUNHA, S. B.; GUERRA, A. J. T. (Ed.). Geomorfologia do Brasil. 4. ed. Rio de Janeiro: Bertrand Brasil, 2006. p. 273-349. ISBN: 8528606708.

NASCIMENTO, Marcos Antonio Leite. Geologia, geocronologia, geoquímica e petrogênese das rochas ígneas cretácicas da província magmática do Cabo e suas relações com as unidades sedimentares da Bacia de Pernambuco, NE do Brasil. Tese (Doutorado em Geodinâmica) - Centro de Ciências Exatas e da Terra, Universidade Federal do Rio Grande do Norte, Natal, 2003.

PROJETO MONITORAMENTO AMBIENTAL INTEGRADO. Avaliação dos processos de erosão costeira nos municípios de Paulista, Olinda, Recife e Jaboatão dos Guararapes relatório final. Recife: Universidade Federal de Pernambuco, 2009. 3 v.

SPO/UFRJ. Espectro de ondas. Atlasul, 2009. Disponível em: <http://www.lamma.ufrj.br/sites/spo/atlasul/ index.php>. Acesso em: 16 nov. 2012.

SUGUIO, Kenitiro. Introdução geral. In: Célia Regina de Gouveia Sousa; Kenitiro Suguio; Antônio Manoel dos Santos Oliveira; Paulo Eduardo de Oliveira (Org.). Quaternário do Brasil. Ribeirão Preto, SP: Holos, 2005. p. 21-27. ISBN: 85-86699-47-0.

Trabalho enviado em fevereiro de 2013

Trabalho aceito em março de 2013 